\author{
CANADA
}

DEPARTMENT OF AGRICULTURE

\title{
STORAGE OF APPLES
}

By

W. R. PHILLIPS

and

P. A. POÁPST

Horticulture Division

Experimental Farms Service

Published by Authority of the Rt. Hon. James G. Gardiner, Minister of Agriculture, Ottawa, Canada 



\section{CONTENTS}

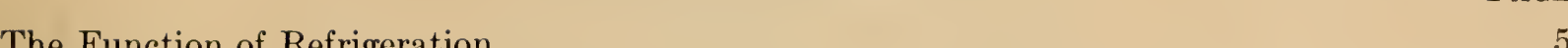

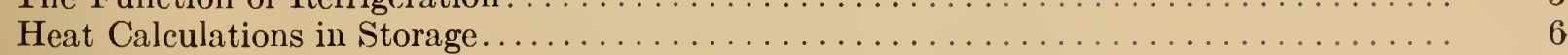

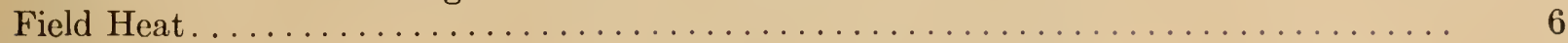

Heat of Respiration . . . . . . . . . . . . . . . . . . . . . . . . . . . . . . . 7

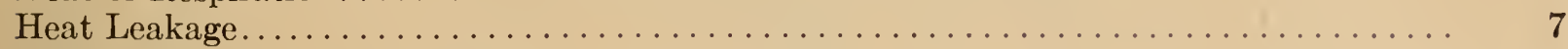

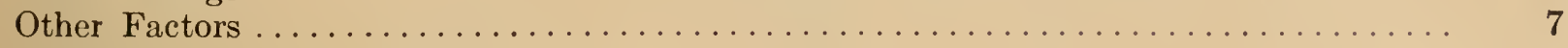

Principles Involved in Cooling. . . . . . . . . . . . . . . . . . . . . . . 8

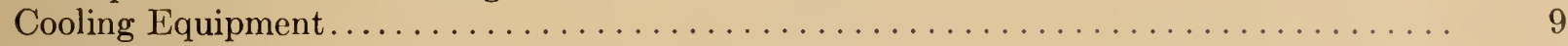

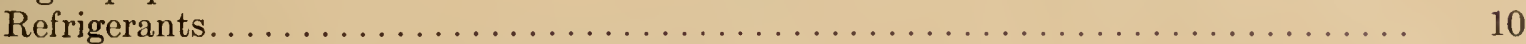

Brine Circulation versus Direct Expansion . . . . . . . . . . . . . . . . . . 11

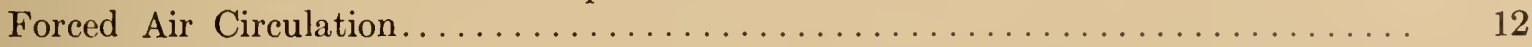

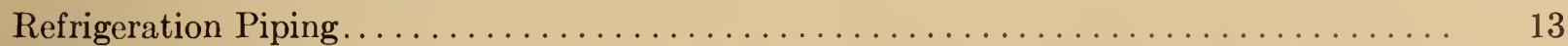

Piping in the Evaporator or Cooling Coils. . . . . . . . . . . . . . . . . . . . . . . . . 14

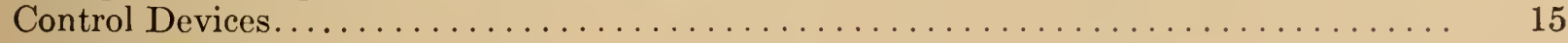

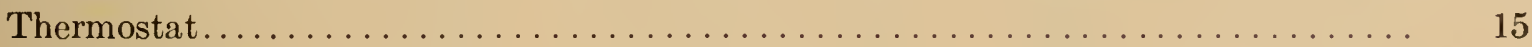

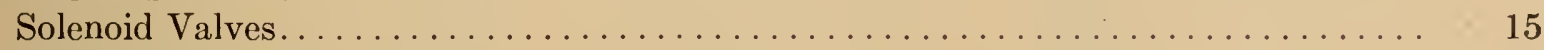

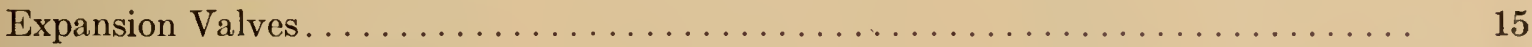

Suction Pressure Regulators. . . . . . . . . . . . . . . . . . . . . . . . . . . 16

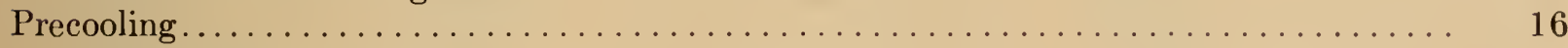

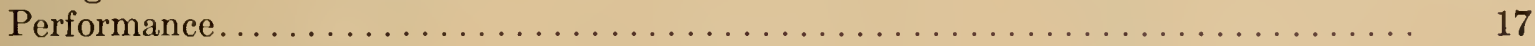

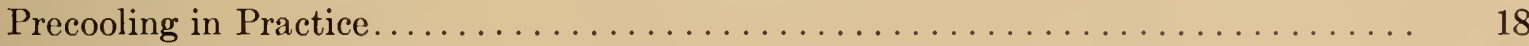

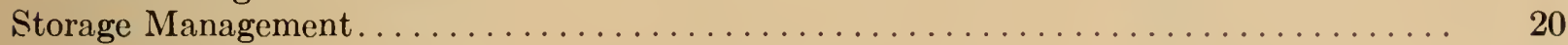

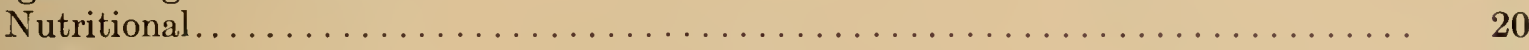

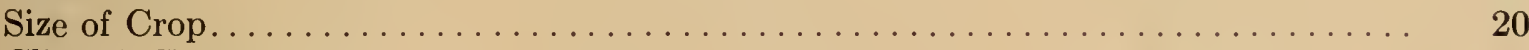

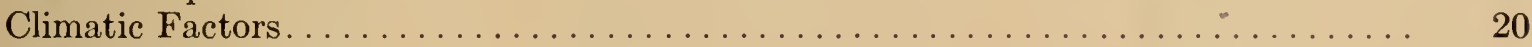

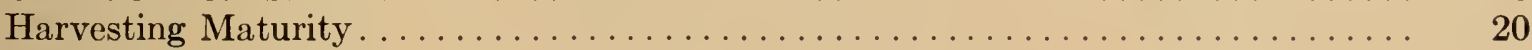

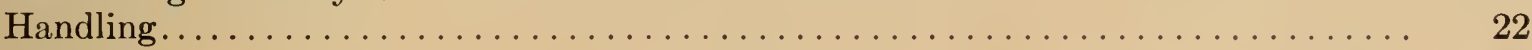

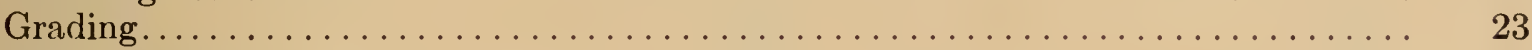

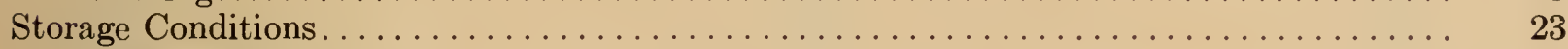

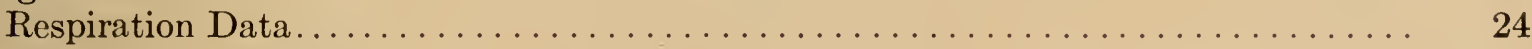

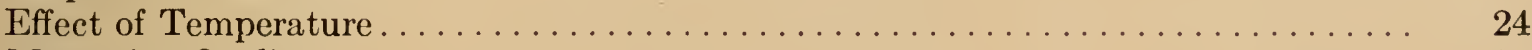

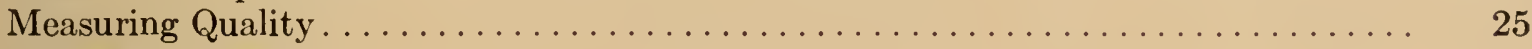

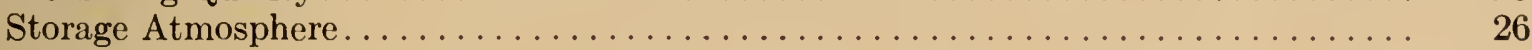

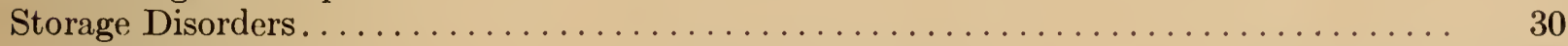

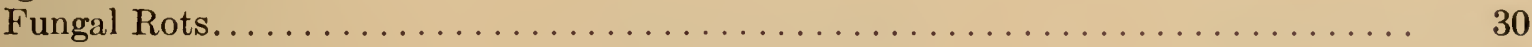

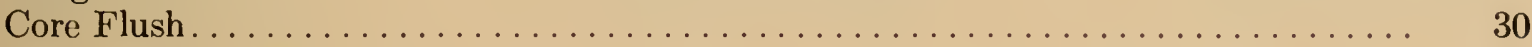

Senile Breakdown . . . . . . . . . . . . . . . . . . . . . . . . . . . . 30

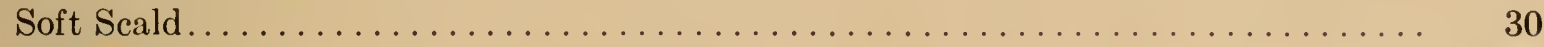

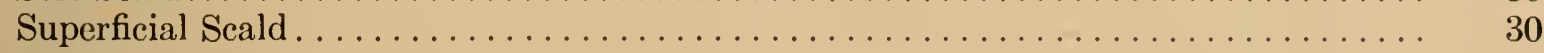

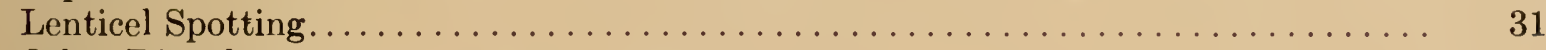

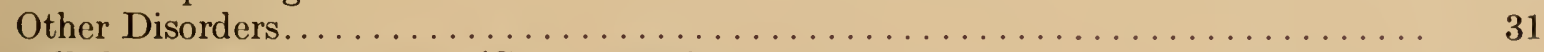

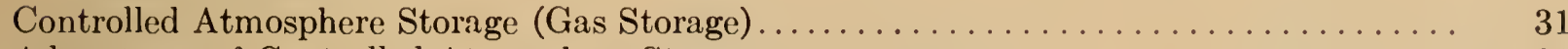

Advantages of Controlled Atmosphere Storage. . . . . . . . . . . . . . . . . . . . 31

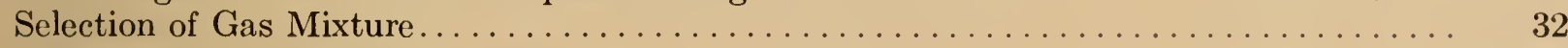

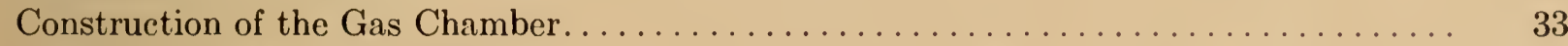

Making the Gas Chamber Tight. . . . . . . . . . . . . . . . . . . . . . . . . 33

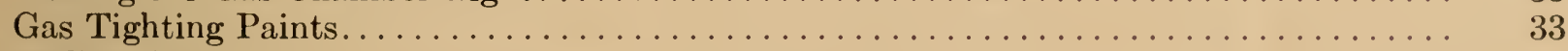

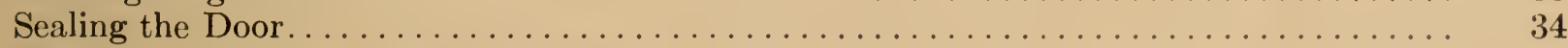

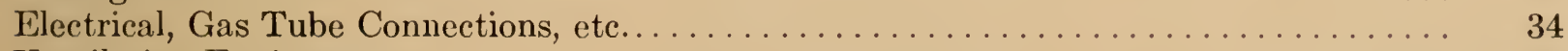

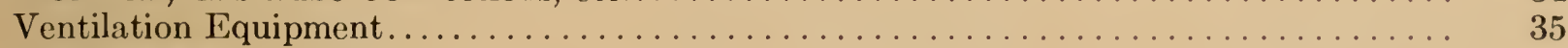

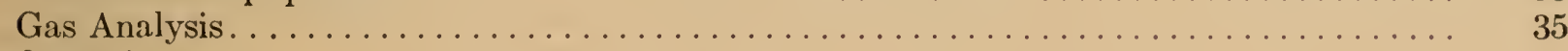

Operation. . . . . . . . . . . . . . . . . . . . . . . . . . . . . . 37

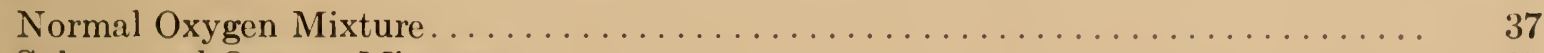

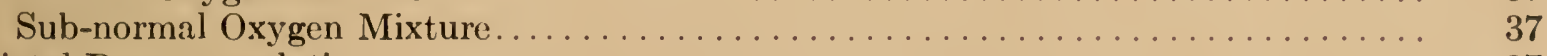

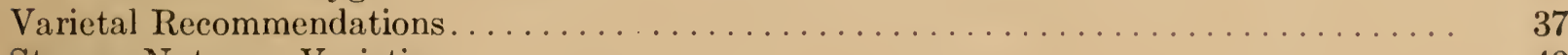

Storage Notes on Varieties. . . . . . . . . . . . . . . . . . . . . . . . . 40 


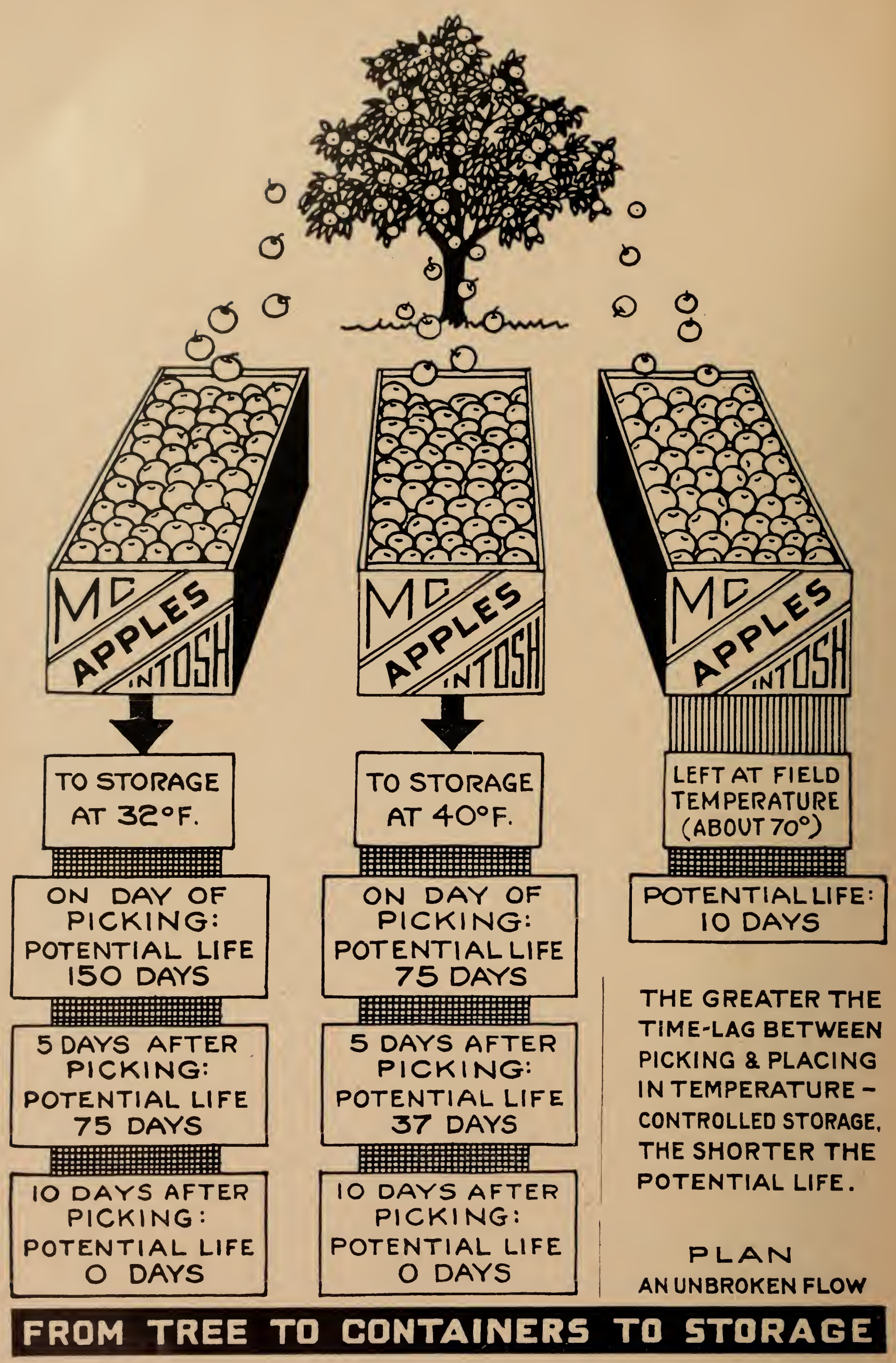




\section{STORAGE OF APPLES}

\section{The Function of Refrigeration}

Apples in the fresh state-whether attached to the tree or not-are living material. This has a bearing on all problems associated with the storage of fresh apples. Since apples are composed of living tissue their structure is made up of small units called cells. These cells must be kept intact and well supplied with food elements, principally sugars, if life is to be maintained. Just as an engine requires fuel, living cells in the apple require sugars to function. The process by which living materials use sugars or other substances for energy is called respiration. This function usually results in the production of carbon dioxide and the consumption of oxygen from the air. This explains the presence of considerable amounts of carbon dioxide often noted in large apple storages that have been kept closed.

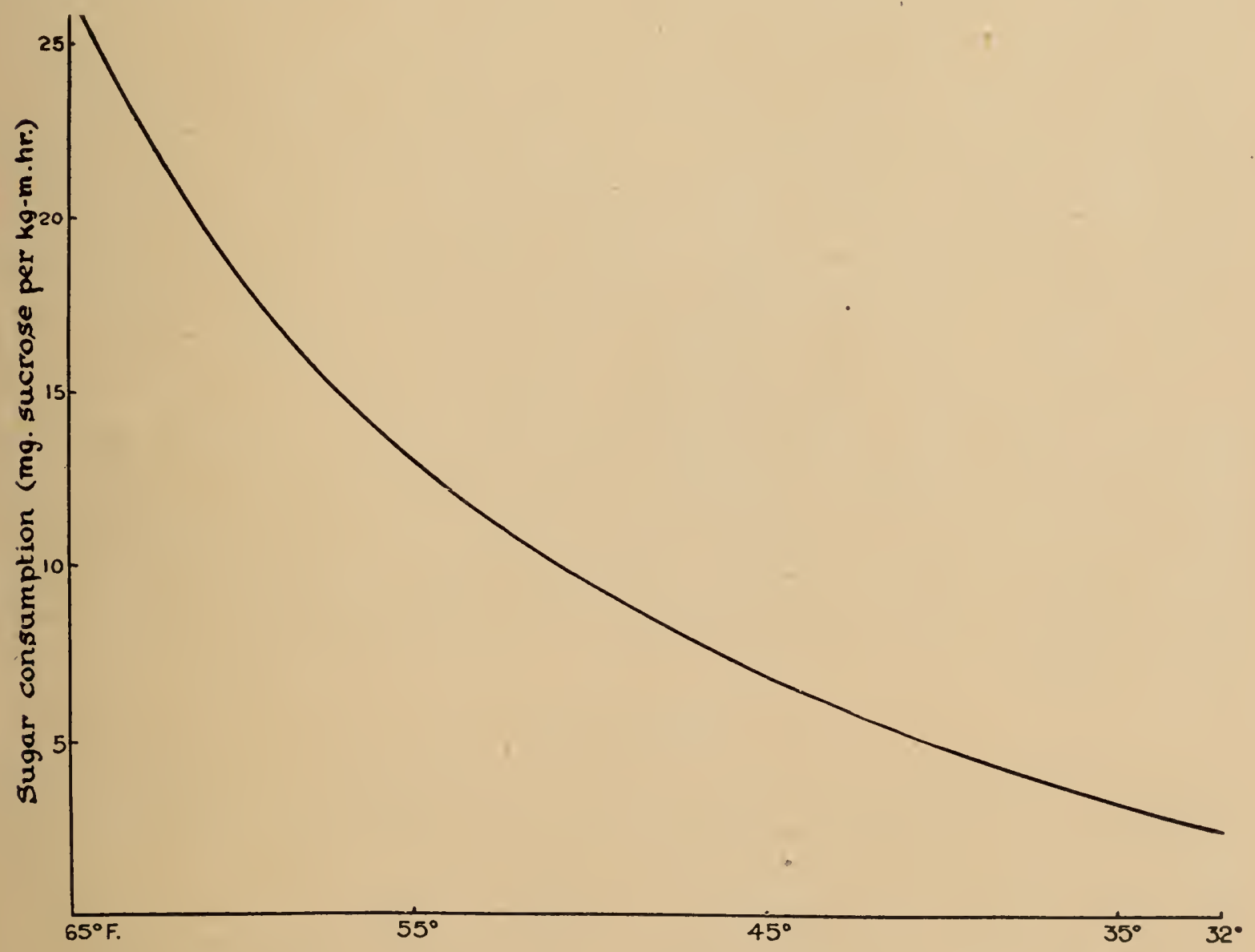

FIG. 1. Consumption of sugar (sucrose) in McIntosh apples at temperautres from $65^{\circ} \mathrm{F}$. to $32^{\circ} \mathrm{F}$. (Calculated on basis of $\mathrm{CO} 2$ output)

Fig. 1 shows how temperature affects sugar consumption by MeIntosh apples. It will be seen from this chart that sugar consumption is seven or eight times as great at $65^{\circ} \mathrm{F}$. as at $32^{\circ}$ to $35^{\circ} \mathrm{F}$. This means that in general (there are exceptions) apples will last seven or eight times as long at $32^{\circ}$ to $35^{\circ} \mathrm{F}$. as they will at $65^{\circ} \mathrm{F}$. Furthermore, this demonstrates the importance of getting apples into storage as quickly as possible. 
It is the apple temperature that governs the length of storage life and not the air temperature of the storage. For this reason the apple temperature should be reduced to the temperature of the storage as quickly as possible. When apples are improperly stored, the air temperature of the room may be reduced to the desired point within twenty-four hours but it may be weeks before the fruit in the centre of the stack actually reaches storage temperature. It is obvious then that such apples will be consuming their reserve food at a much more rapid rate than is necessary, resulting in a much shortened storage life. This emphasizes the necessity of getting apples down to the proper storage temperature as quickly as possible and of holding the fruit at this temperature.

\section{Heat Calculations in Storage}

It is natural to think of cold storage equipment in terms of cooling capacity. This frequently leads to misconception and error. In order to understand refrigeration problems the process must be looked upon as one of heat removal. Heat is a positive form of energy, which can be measured and regulated; and the cooling system, whether mechanical or natural, may be regarded as a pump which draws the heat out of the storage. The suction of this so-called pump can be both controlled and calculated.

The most common measurement of cooling-plant capacity is what is known as the standard refrigeration ton. A cold storage machine of one ton capacity produces the same amount of cooling as melting a ton of ice each day. Technically speaking, this amounts to removing 288,000 B.t.u. per day. B.t.u. stands for British thermal unit. Just as gasoline is measured by the gallon or butter by the pound, so heat is measured by B.t.u. and one B.t.u. is the amount of heat required to raise one pound of water one degree fahrenheit.

The primary function of any apple storage, however cooled, is to remove heat from the product. This function is opposed by three main heat sources (1) heat resulting from initial high temperatures of the product called field heat, (2) heat developed as a result of living processes in the product called heat of respiration and (3) heat leakage through the walls, floor, and roof of the building referred to simply as heat leakage. These heat sources added to other extraneous factors such as heat from lights, workmen, etc., make up the heat load of the plant. All these can be calculated on the basis of B.t.u. per day.

\section{Field Heat}

Field heat represents by far the largest proportion of the refrigeration load in the average apple storage. This is the actual heat contained by the apples in excess of their storage temperatures. In other words it is the amount of heat that must be withdrawn from the fruit to reduce it to storage conditions. In order to compute this heat load the maximum daily input of apples must be known. It is also important to know the probable maximum temperatures at which these will be harvested. Since apple tissue is largely water, it may be assumed that the removal of one B.t.u. will reduce the temperature of one pound of apples one degree Fahrenheit.

A maximum daily input of one thousand bushels at a temperature of $80^{\circ} \mathrm{F}$. to be cooled to $32^{\circ} \mathrm{F}$. would represent 45,000 pounds to be cooled $48^{\circ}(80-32)$. Thus the maximum daily field heat load is $2,160,000$ B.t.u. $(45,000 \times 48)$. On the basis of 288,000 B.t.u. per ton this represents a heat load of about $7 \frac{1}{2}$ tons of refrigeration. Thus the method for determining field heat load in tons of refrigeration is as follows: (weight of apples, pounds) $\mathrm{x}$ (difference between harvest and storage temperature) $\div 288,000$. 


\section{Heat of Respiration}

This source of heat is continuous throughout the storage life although the heat load may be decreased with lowered temperatures. A ton of apples at $85^{\circ} \mathrm{F}$. generates about 11,000 B.t.u., at $40^{\circ} \mathrm{F}$. about 1,400 B.t.u., and at $32^{\circ} \mathrm{F}$. about 700 B.t.u. daily. Thus under maximum respiratory conditions this amounts to $\cdot 04$ tons of refrigeration per ton of apples, and under storage conditions to only about $\cdot 0024$ tons daily. This might appear insignificant but a small storage of 25,000 bushels (562 tons) will require approximately $1 \frac{1}{2}$ tons of refrigeration. Of course this is small compared with the field heat load but it is large enough to warrant consideration.

\section{Heat Leakage}

Heat leakage is the amount of heat that filtrates through the walls, ceiling and floor of the storage room, and unfortunately is usually greatest when the demand for field heat removal is at its peak. Insulation is used to help control this. In an uninsulated or poorly insulated storage, heat leakage is excessive and may over-tax the refrigeration equipment to the extent of jeopardizing the welfare of the fruit in storage. Insulation is a separate subject and only the essentials necessary to calculate heat leakage will be mentioned here. Corkboard is the most common form of insulation and is almost universally accepted as a standard. The usual amount applied is 4 inches in the walls, 3 to 4 inches under the floor and 6 inches in exposed ceiling (i.e. under the roof).

In any building heat will pass from warmer to colder regions. In a refrigeration plant, in warm weather, heat passes from the outside to the interior or colder regions. This is referred to as heat infiltration and has to be removed by the refrigeration plant. Thus it is important to know the probable maximum heat infiltration in order to compute refrigeration capacity.

Let us assume that we have a building with an internal surface area of 1,000 square feet, insulated with 4 inches of cork, that the storage is operated at $32^{\circ} \mathrm{F}$, and the maximum outside temperature is $80^{\circ} \mathrm{F}$. From insulation tables we find that cork has a $\mathrm{K}$ value of $\cdot 3(\cdot 3$ B.t.u. per square foot per degree temperature difference per hour for each inch in thickness). Thus 1,000 square feet would permit the infiltration of 300 B.t.u. per hour $(1,000 \times \cdot 3)$ if the cork were 1 inch thick and the outside temperature were $1^{\circ}$ higher than inside $\left(33^{\circ} \mathrm{F}\right.$. outside, $32^{\circ} \mathrm{F}$. inside). Four inches of cork reduces this infiltration figure to $\frac{300}{4}$ or 75 . Since the outside temperature is $80^{\circ}$ the infiltration is increased 48 times $(80-32)$. Thus the hourly infiltration of heat for the storage is $75 \times 48$ or 3,600 B.t.u. Since one ton of refrigeration is required for 12,000 B.t.u. infiltration (basic engineering information), the storage in question would require 3 ton $\frac{(3,600)}{12,000}$. Similarly other heat infiltration calculations have to be made for cenlings, floors, and walls, because of the difference in temperatures adjacent to these areas.

\section{Other Factors}

Lights, door openings, electric motors, etc., all constitute sources of heat. In exceptional instances these have to be given special consideration. If, however, field heat, heat leakage, and heat of respiration are amply provided for the surplus would take care of these factors. By far the largest heat load is in the fall of the year when the storage is being filled with apples. Once these are cooled down and outside temperatures fall the heat load very nearly vanishes. This is shown in Fig. 2. It will be noted that heat leakage in A and B

$60847-2$ 
are the same. As the temperature drops the surplus of 68.6 per cent as shown in $\mathrm{B}$ will continue to increase. When outside temperatures are at $32^{\circ} \mathrm{F}$. (storage temperature) or lower, heat leakage will be eliminated. Under this last condition the total operating load will be less than 2 per cent of the maximum. This theoretical condition may not be approached but it is usually assumed that the amount of refrigeration required at loading is ten times the amount needed cluring the winter.
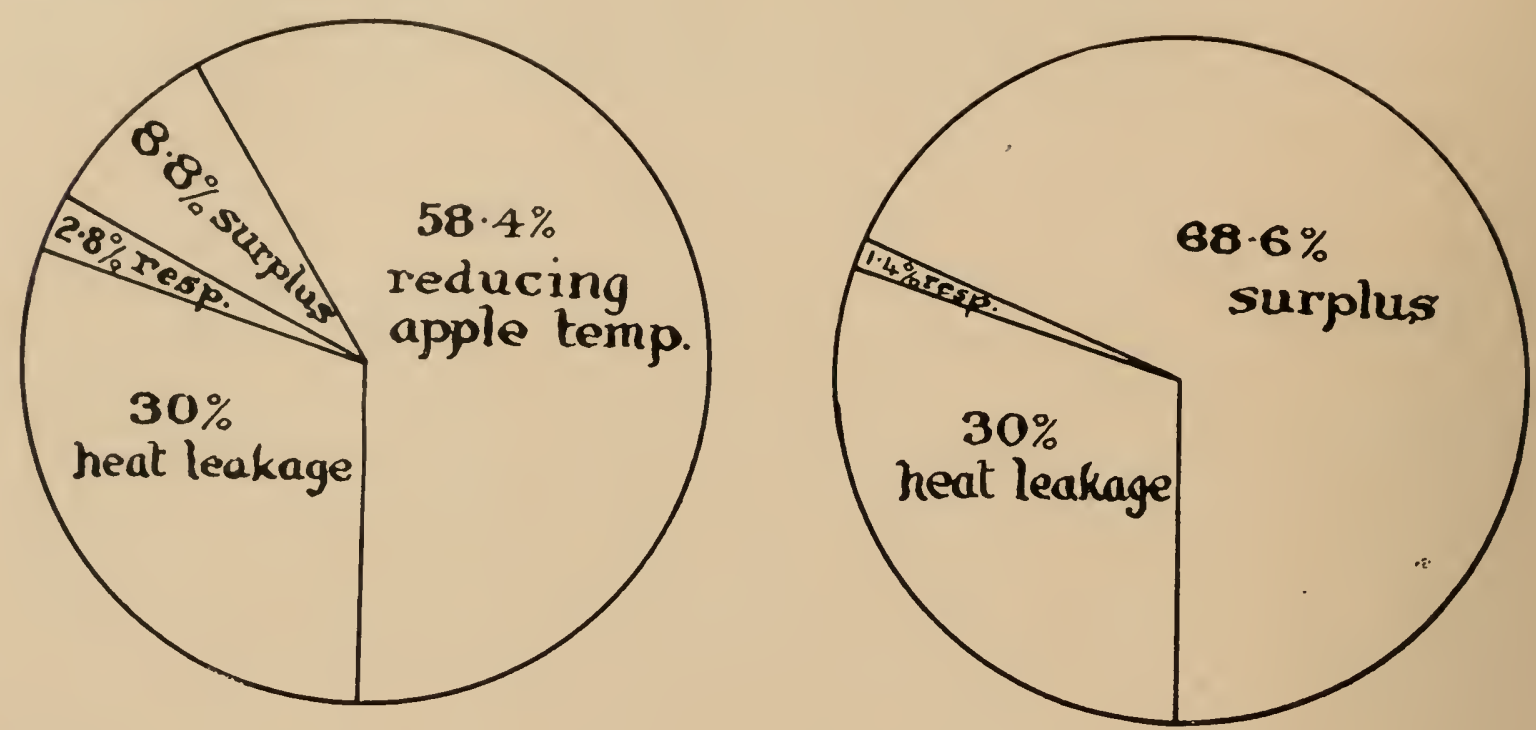

FIG. 2. Distribution- of heat load, on left (A) at loading time, and right (B) after the load is cooled. These figures are calculated on theoretical conditions which according to practical observations are typical.

\section{Principles Involved in Cooling}

The least expensive means of cooling apples is with outside air. The weakness of this method is that its success depends on weather conditions. In spite of this, fairly satisfactory results may be obtained by using outside air for cooling. Careful management is essential to take advantage of cool nights and days. Even so, a long warm fall will occasionally cause serious difficulties. To use this form of cooling for late apple varieties, a well insulated building is essential. Rapid and uniform air exchange is best carried out by the use of a fan. This should be capable of changing the air in the storage every three minutes. Care should be taken to stop the air exchange system when the outside air is warmer than the apples.

Second in cost is the method of using ice to cool the storage. This involves the use of an ice bunker over which the air from the storage circulates either by fan or convection. In order to obtain maximum efficiency costly air circulation and bunkers are required to melt the ice rapidly enough to produce sufficient cooling. This method is seldom used.

Mechanical refrigeration is more expensive; but is by all means the most satisfactory if properly applied. In spite of the high cost in many apple growing areas, mechanical refrigeration is essential to the industry because it is easily controlled and operates more or less independently of weather conditions. Fundamentally this form of refrigeration depends on cooling by evaporation. Certain liquids called refrigerants require a large amount of heat in the process of evaporation. By thus absorbing heat, cooling is produced. Ammonia is the most common commercial refrigerant, particularly in larger installations. The principle of refrigeration might be more easily understood by consulting Fig. 3. 


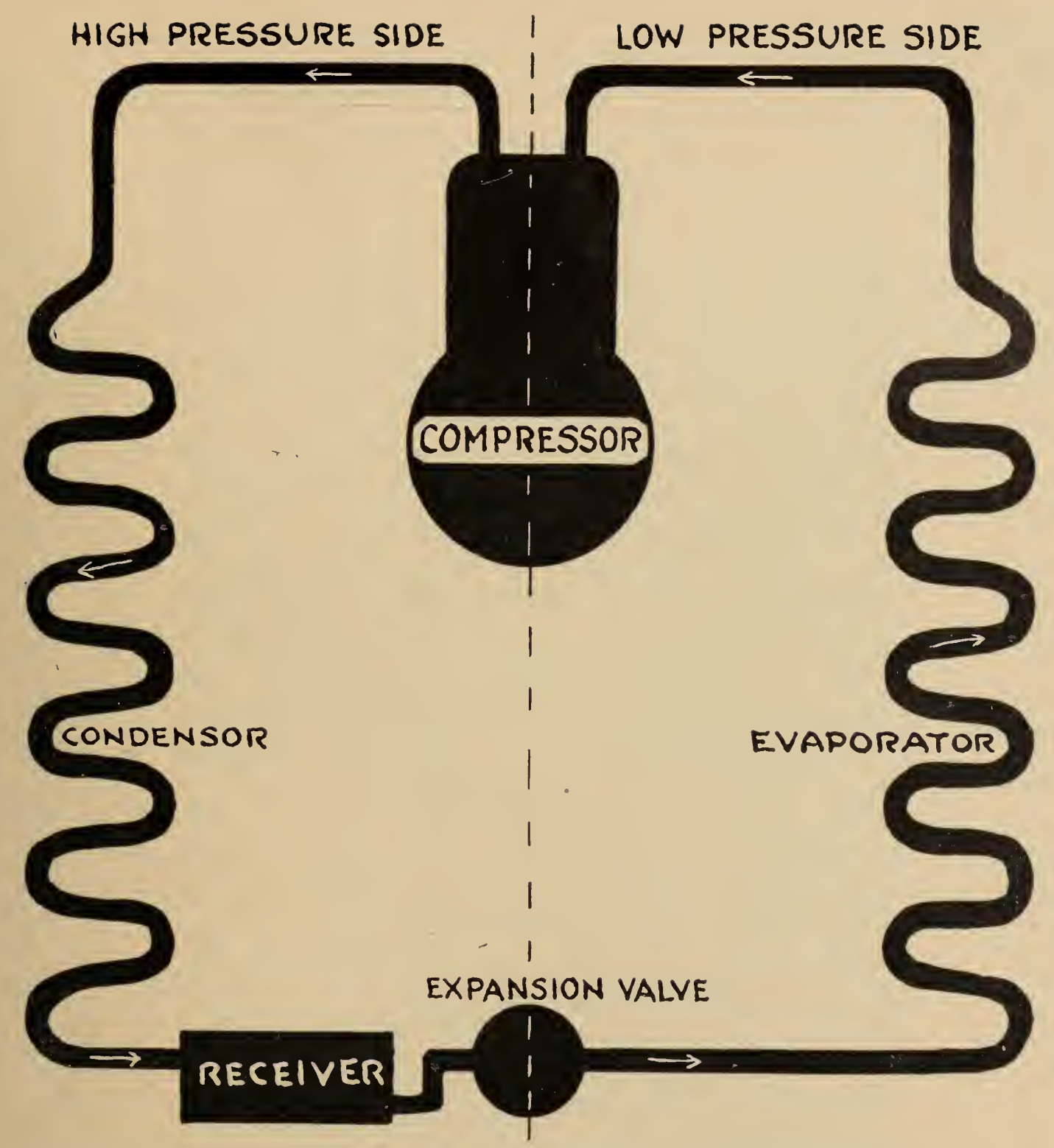

FIG. 3. Refrigeration cycle in ordinary compression system.

Liquid ammonia in the receiver under pressure goes through the expansion valve. Here it evaporates under low pressure existing in the evaporator where cooling is produced. The compressor, which is simply a circulating pump, pumps the gas out of the evaporator into the condenser. In the condenser, heat is given off, changing the refrigerant from a gas to a liquid, when it passes back to the receiver and the cycle is continued.

\section{Cooling Equipment}

In choosing the type of cooling equipment several alternatives are possible; but the equipment selected will likely be satisfactory if it is properly engineered. Nevertheless a more intelligent appraisal can be made if the principles involved in the different types are known. The compression system is the most common. This involves the principle shown in Fig. 3. The absorption system has its most common application in small household refrigerators, particularly in localities where electricity is not available. In the future this system may have more general application, but at present practically all commercial refrigeration equipment is of the compression type.

$60847-2 \frac{1}{2}$ 


\section{Refrigerants}

Of the dozen or so refrigerants on the market, two-ammonia and dichlorodifluoromethane (Frcon 12) -are the most suitable. The others are for exceptional types of refrigeration, and small units of household type.

Ammonia.-Ammonia has long been regarded as the standard commercial refrigerant. It is reasonable in price, has high latent heat propertics (565 B.t.u. per $1 \mathrm{~b}$. at $5^{\circ} \mathrm{F}$.) and does not corrode steel. It does not mix with oil, making it easy to separate the refrigerant from the lubricant in the system. Of the high pressure refrigerants (having normal condensing pressures in excess of 125 pounds gauge pressure) ammonia is about the lowest. 'This is important because, the higher the pressure, the stronger the metal required for compressors, condensers, piping, etc.

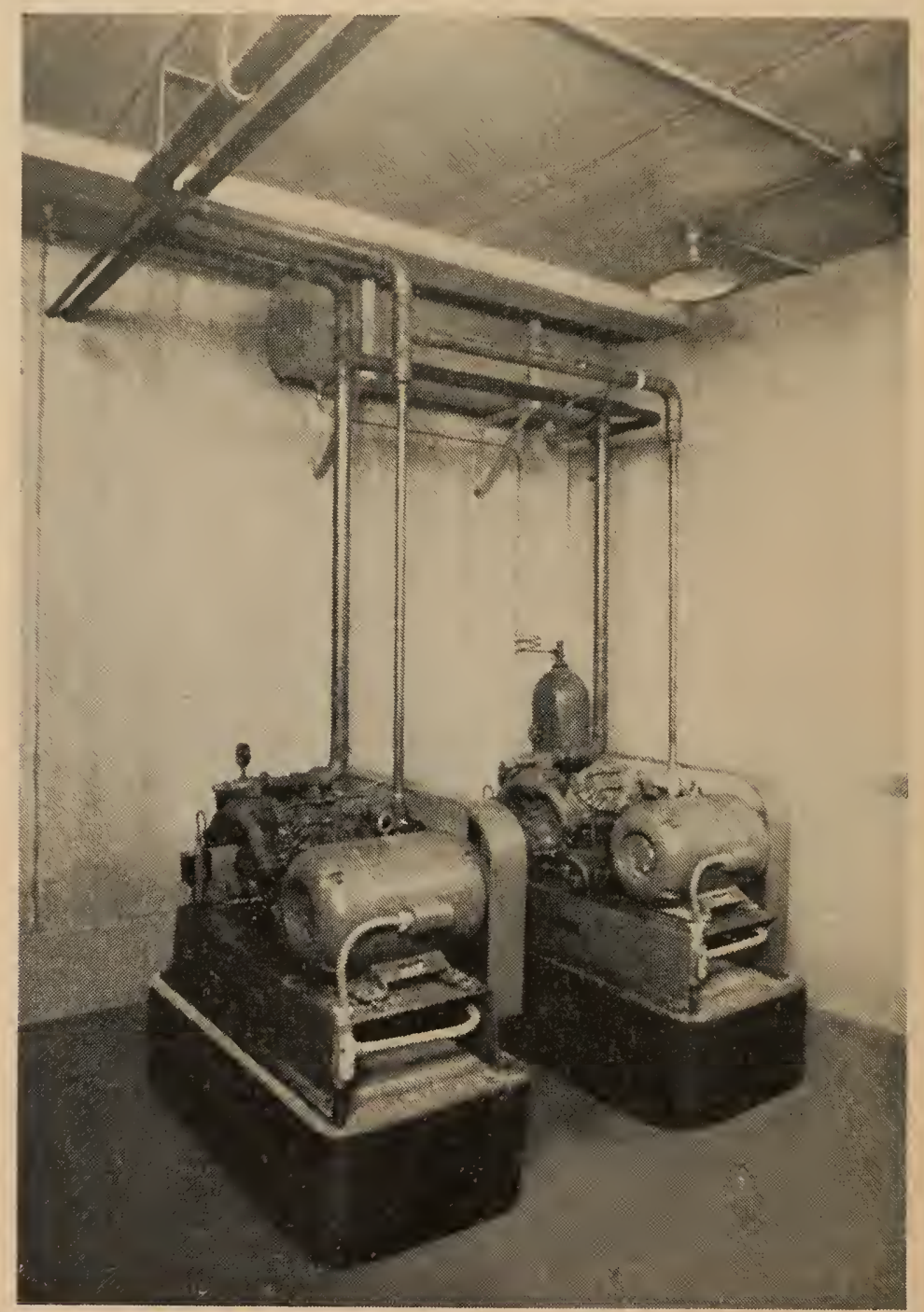

FIG. 4. Condensing Units-Two Freon condensing units are shown. These are connected in parallel. Surge tank on return line can be seen in upper right hand corner.

The greatest disadvantage of ammonia, besides high pressure, is its toxicity both to products stored and to storage personnel. Fortunately slight leaks can be detected readily by smell, but apples exposed to ammonia fumes, even for a short period, will be damaged. If the damage is slight, apples will recover if the storage is aired immediately. The likelihood of such leaks has been reduced considerably by modern welding and pipe fitting.

Freon.-Freon 12, previously used chiefly in small units, has been found suitable for large installations also and is now regarded as a universal type. It is considerably more expensive than ammonia but this is offset somewhat by 
the fact that it is a low pressure refrigerant (normal condensing pressures from 80 to 110 pounds gauge pressure), requiring a lighter retaining metal than ammonia. Modern engineering techniques almost preclude the possibility of losses through leaks. The greater density of Freon compensates for its lower latent heat, $69 \cdot 47$ as compared with 565 for ammonia. From 12 is non-toxic and non-corrosive to metals although it dissolves rubber and certain other organic compounds.

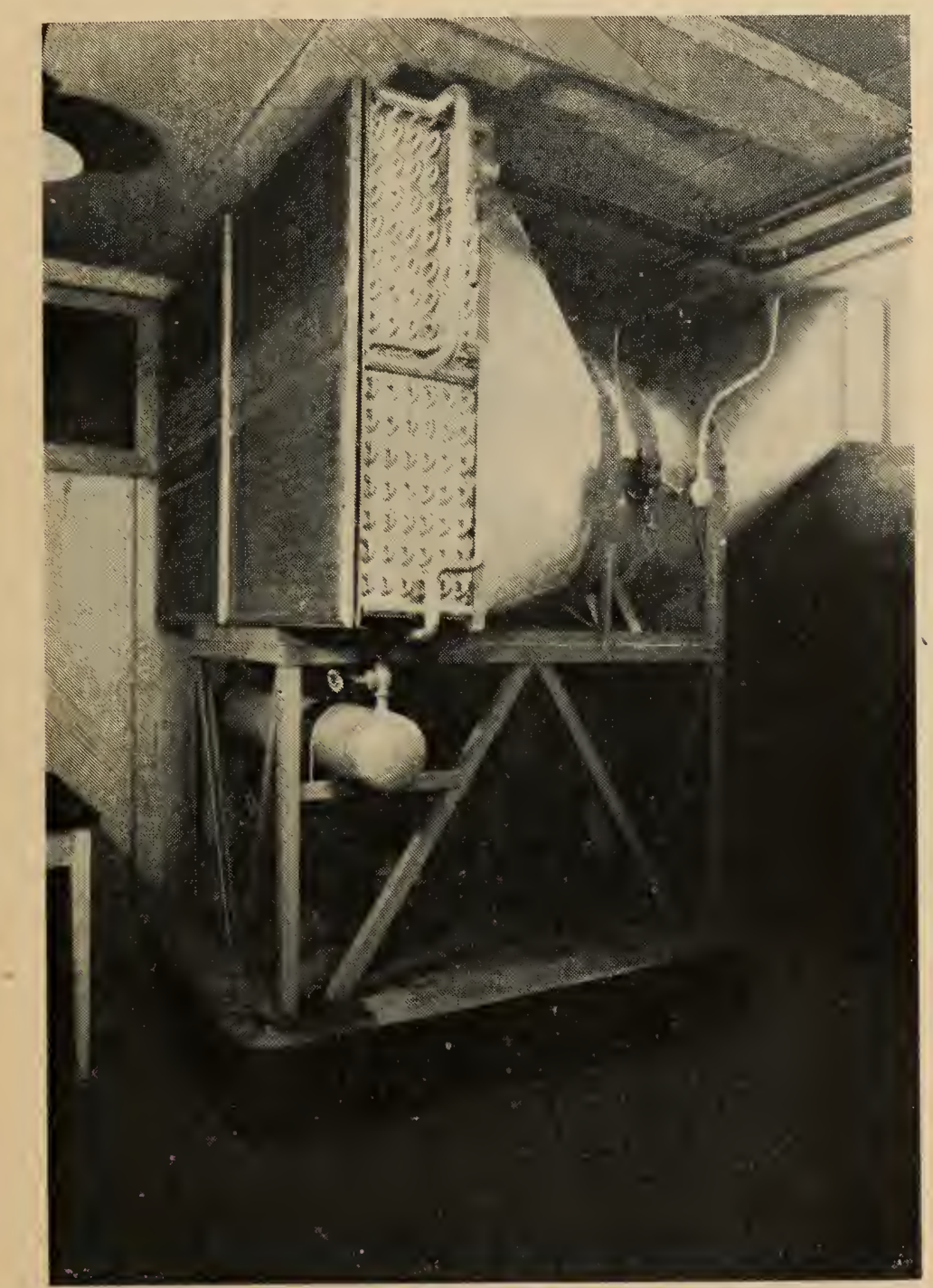

Fig. 5. Large type air cooled condenser. Usually water cooled condensers are used for units over 3 H.P. There is no limit, however, for the use of air cooled units when water supply is critical.

Brine Circulation versus Direct Expansion.-The refrigcrant can be used in two different ways. In the brine circulation system it can be used to cool a liquid of low freczing point, usially calcium chloride brine. This in turn is circulated through cooling coils in the room. With the direct expansion system the refrigerant is evaporated directly within coils in the room. Direct expansion is by far the more popular type of cooling although brine circulation has certain advantages.

Brine lends itself to closer temperature control since the temperature of the brine itself ean be more easily regulated. With brine circulation there is very little danger of toxic refrigerant fumes reaching the product when leaks occur. One objection to brine is that it involves greater capital outlay for brine tanks or coolers, circulating pumps, etc. Another is that brine is corrosive to metals. 
causing high maintenance costs. This can be controlled to a certain extent by correcting the pH and by the addition of chromates, but this does not entirely eliminate corrosion in practice.

On the other hand, with modern engineering practices, many of the disadvantages of direct expansion have been overcome. Leakages can be largely eliminated by modern welding and soldering methods. There is a tendency to get lower temperatures near the expansion valve than at other parts of the coil, but such devices as back pressure control valves and surge tanks assist in maintaining uniform temperatures throughout the length of the cooling coil.

Regardless of refrigerant or whether it be direct expansion or brine, the cooling unit may be classed either as a forced air or convection system. In the former, air from the storage room is forced, by a fan, over cooling coils and returned to the room, whereas in the latter the cooling pipes are suspended from ceiling or walls, and the cooled air is carried by normal air movement or convection to other parts of the storage room.

Forced Air Circulation.-The more quickly the storage air passes over the surface of the cooling pipes the more rapid the cooling effect. If air is blown by a fan over the cooling coils, for example, the room temperature falls more quickly than if the air is still. Thus much less pipe is required to produce a given refrigeration effect if air is forced over the cooling pipe. A forced-air system requires about $\frac{1}{3}$ (or less) the amount of pipe required for the convection type cooler. For this reason forced air systems have gained in popularity.

Wetting the coils also speeds up refrigeration. At higher temperatures (over $35^{\circ} \mathrm{F}$.) the cooling coils are sprayed with water. At temperatures below $35^{\circ} \mathrm{F}$, commonly found in apple storages, brine is sometimes used. Spraying the coils with brine has many undesirable effects, such as corrosion, and the carry over of brine spray into the storage room.

The trend, therefore, has been towards dry coils, using forced draft, but without brine spray these coils are inclined to accumulate frost, hindering heat transfer and air flow. To correct this, water or electric defrost appliances are commonly used. In water defrosting a water spray is turned on, and the refrigeration and ventilation equipment shut off. When defrosting is complete the water is shut off and refrigeration returned to normal. The electric defrost works in the same way, except that a heating element built into the cooling unit supplies the heat to melt the ice. The latter is more rapid and, as well, precludes the possibility of a water freeze-up in drains, etc. Hot gas from the condenser is used in a third method of defrosting. This system is frequently referred to as "the reverse cycle" and may be controlled automatically.

Forced air units may be of the smaller ceiling-mounted, or the larger floor-mounted type. The ceiling-mounted unit consists of a grill, very similar to an automobile radiator with a blade-type electric fan. This fan blows air from the storage through the grill where it is cooled. It is convenient for smaller rooms, because it saves floor space and is easy to control.

In larger storage rooms, 3,000 cubic feet or more, floor-mounted models are commonly used. The cooling coils are enclosed in a metal cabinet with an opening at the bottom and a fan with discharge openings at the top. Storage air is drawn in at the bottom, passes over the coils and is discharged by the fan at ceiling height. (See Fig. 6). Different types of floor-mounted units are available, depending on the refrigeration required. In rooms that are large or irregularly shaped, ducts may be needed. In multi-room units where one cooler 
supplies cold air for more than one room the fan should also be floor-mounted. In this case the discharged, refrigerated air is delivered to large ducts or plenums that distribute the air to the various rooms.

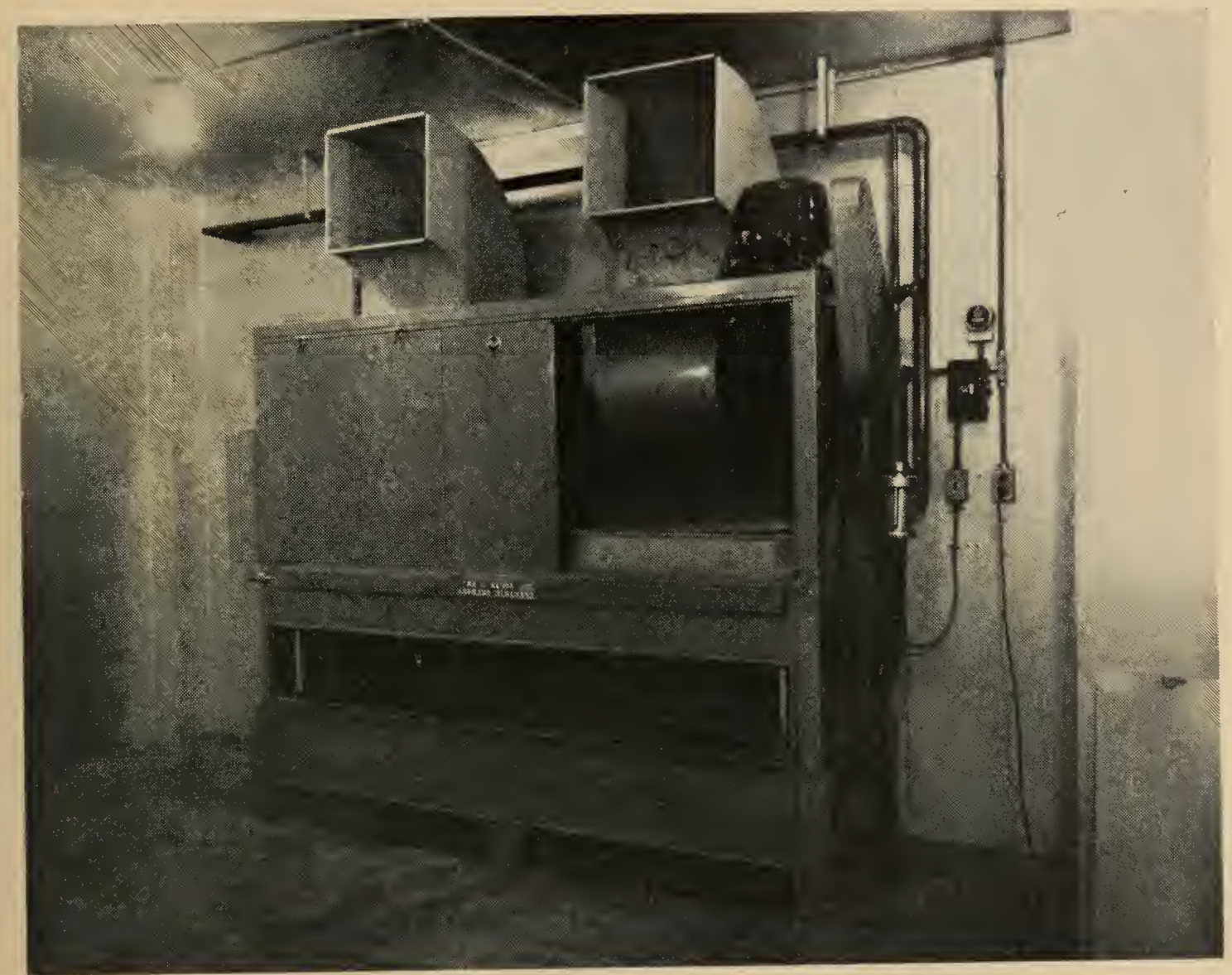

FIG. 6. Floor-mounted blower coil unit. Air is admitted at lower opening and discharged at cowl opening at top. Front cover-plate is removed to show one of the two fans.

Whatever the type of cooling unit, it must be engineered properly. The most common "short-cut" is to skimp on the amount of cooling surface. This may provide the desired temperature but results in desiccation of the apples as well as low compressor efficiency. The amount of cooling surface is directly related to the load, this in turn varies so much both during the time of storage and from one storage to another that no set figure can be given. The best safeguard in drawing up a contract is to stipulate to the installing engineer that the humidity be not less than 90 per cent.

\section{Refrigeration Piping}

Some form of piping is required to conduct the refrigerant, whether liquid or gas, from the receiver to the evaporator and back to the compressor, condenser, and receiver again. It is important that the pipes resist corrosion and withstand pressures. For ammonia or brine, wrought iron or stecl and seamless steel are used. Copper pipe or brass (yellow or red) are commonly used for low pressure refrigerants. These are convenient because of their flexibility compared with iron or steel, making it possible to bend and coil the smaller piping as required. They have proved adequate for withstanding the normal pressures encountered with low pressure refrigerants. Another feature is that they can be internally dehydrated and sealed, thus aroiding the introduction of excess moisture into the refrigeration system. 


\section{Piping in the Evaporator or Cooling Coils}

In the older type of storage room a battery of pipes hung from the ceiling or walls constituted the cooling coils. For certain jobs this type of installation is still faroured. More recently, extended surface pipes are being used, usually in the form of rectangular plates or "fins" around the pipe. These conduct heat from the room to the coils, speeding up heat transfer, and resulting in more effective cooling with a shorter length of pipe. For

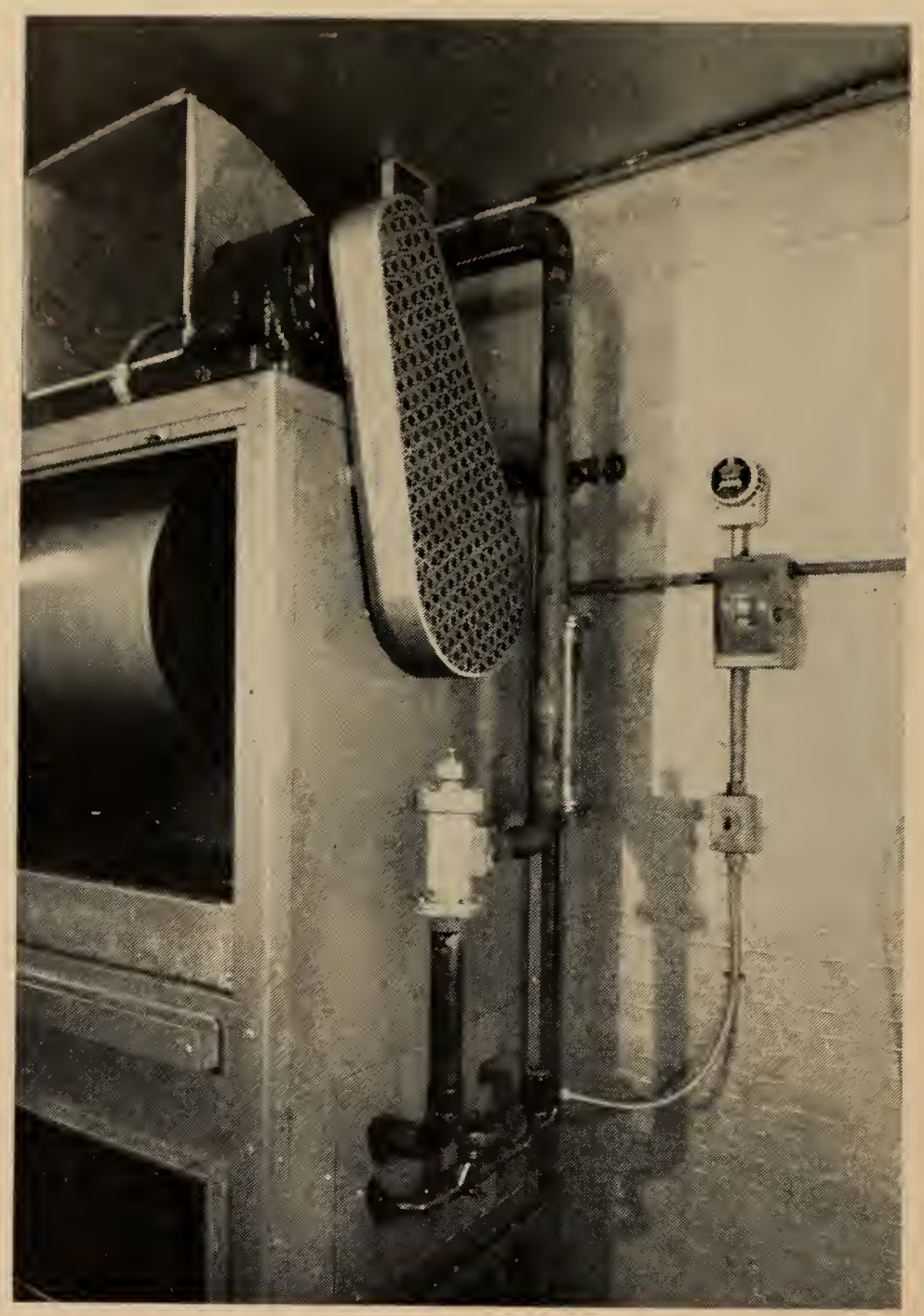

Fig. 7. Partial view of floor-mounted blower coil unit, with cover removed to show fan and cooling coils. Note suction pressure regulator at elbow junction of large pipe at the side of unit.

effective heat transfer these fins must be closely attached to the pipe. Another type of extended surface pipe is made by cutting and raising slivers off the surface of the pipe. Since slivers are attached perpendicularly to the pipe surface, they give the pipe a "spined" appearance, and a very effective conducting surface. However, one serious objection to fins or spines is that condensed moisture freezes between them making the extended surface ineffective.

Still another form of "extended surface" is the cooling plate, comprising flat surfaces with sufficient space between for the circulation of the refrigerant. It is most commonly used in low temperature or freezer installations. 


\section{Control Devices}

The object of control devices in storage is primarily to maintain uniform temperatures. This can be done either directly by using a thermostat or indirectly by controlling the pressure of the refrigerant in the evaporator. For most efficient control both should be used. An effective control system is shown in Fig. 8. The solenoid on the suction is not altogether necessary, though the presence of two solenoids will provide complete isolation of the evaporator in the off cycle.

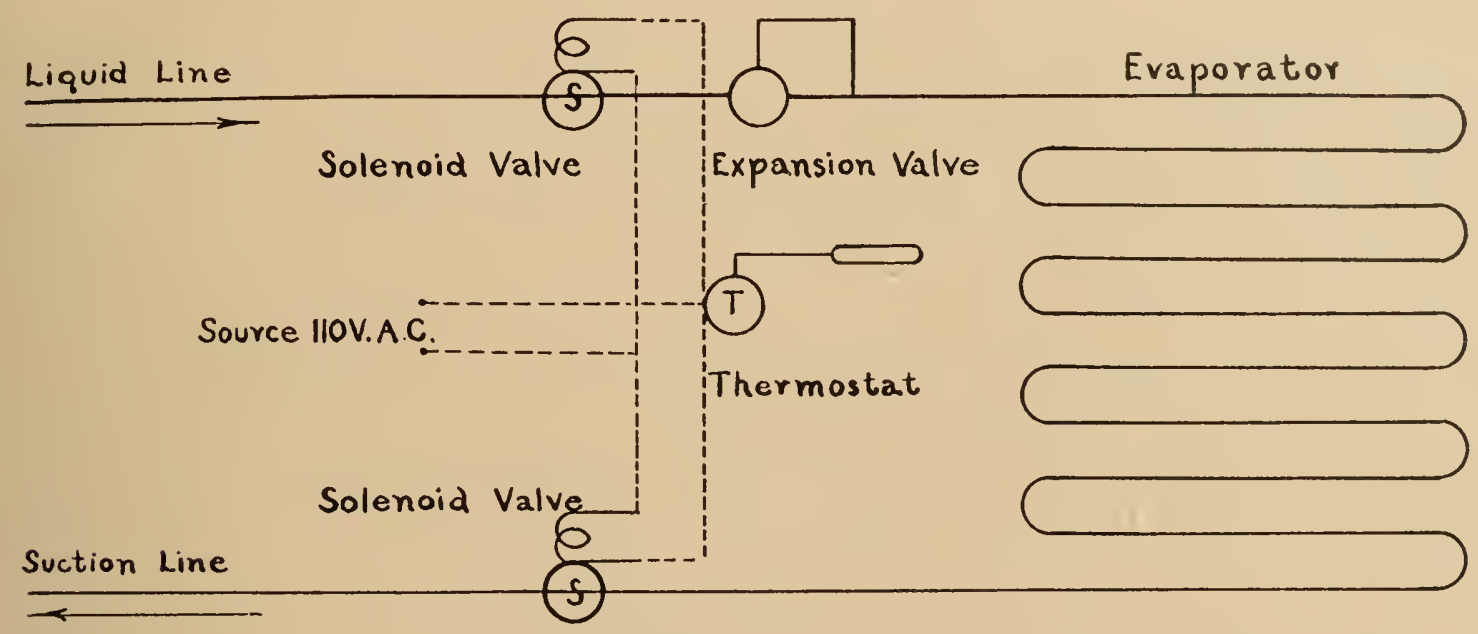

FIG. 8. Layout of Control System for Refrigeration. The thermostat closes the electric circuit thus opening the solenoid valves, permitting the flow of refrigerant through the pipes of the evaporator. The suction pressure regulator restricts the flow of return gas according to the pressure in the evaporator.

\section{Thermostat}

The thermostat is a spring-balanced electric switch, which is closed by a rise in temperature. The actuating mechanism can be either gas or metal which expands when the temperature increases. The important features are dependability and sensitivity. The latter should be of the order of $1^{\circ}$ or less. This means that if set at $32^{\circ} \mathrm{F}$. the solenoid(s) will close at $31 \cdot 5^{\circ} \mathrm{F}$. and open at $32 \cdot 5^{\circ} \mathrm{F}$. when a temperature of $32^{\circ} \mathrm{F}$. is desired.

\section{Solenoid Valves}

These valves are usually of the globe type, which are opened by an electromagnct and closed by gravity upon the de-encrgizing of the magnet. In this way the flow of refrigerant is started or stopped by the action of the thermostat.

\section{Expansion Valves}

These function in a manner similar to a carburetor in an automobile engine. The liquid refrigerant passes through a small opening or port, thus inducing "atomization" and subsequent rapid evaporation. The selection of the port size (usually stamped on the side or top of the expansion valve) is dependent on the tonnage capacity of the system and the type of refrigerant. Modern expansion valves are so constructed that temperature reductions cause a restriction in the flow of refrigeration through the valve. This aids in the maintenance of more uniform temperatures and pressure in the eraporator.

$60847-3$ 


\section{Suction Pressure Regulators}

These devices are on the suction line near the evaporator. Like the temperature-actuated expansion valves, their function is to prevent suction pressures from going too low. The minimum pressure in the evaporator is adjustable by a hand-operated regulating device. One drawback in mechanical refrigeration is the loss of moisture through condensation on the evaporator. The amount of condensate increases with the temperature differential between storage and eraporator surface. Thus any device which maintains a high suction pressure will conserve moisture loss from the stored product.

In addition to the devices already described, the compressor should be controlled by suction pressure. This is merely a starting switch for the motor actuated by the suction pressure on the line. The "cut-in" and "cut-out" points are adjustable. These should straddle the minimal operating pressures of the eraporator(s). In a multiple set-up the cut-in point should be slightly below the pressure required for maintaining the temperature in the coldest room. A surge tank is usually a necessity in the control set-up. A tank device on the suction line enlarges the volume of the low pressure region, thus preventing frequent starting and stopping of the compressor. The compressor can also be actuated by a thermostat. This makes for more positive functioning but results in frequent starting and stopping of the compressor when a close differential is employed on the thermostat. Furthermore, on multiple set-ups complicated electric wiring is involved.

\section{Precooling}

Precooling is the term applied to the process of quickly reducing a commodity to, or close to, storage temperature, previous to storage or transport.

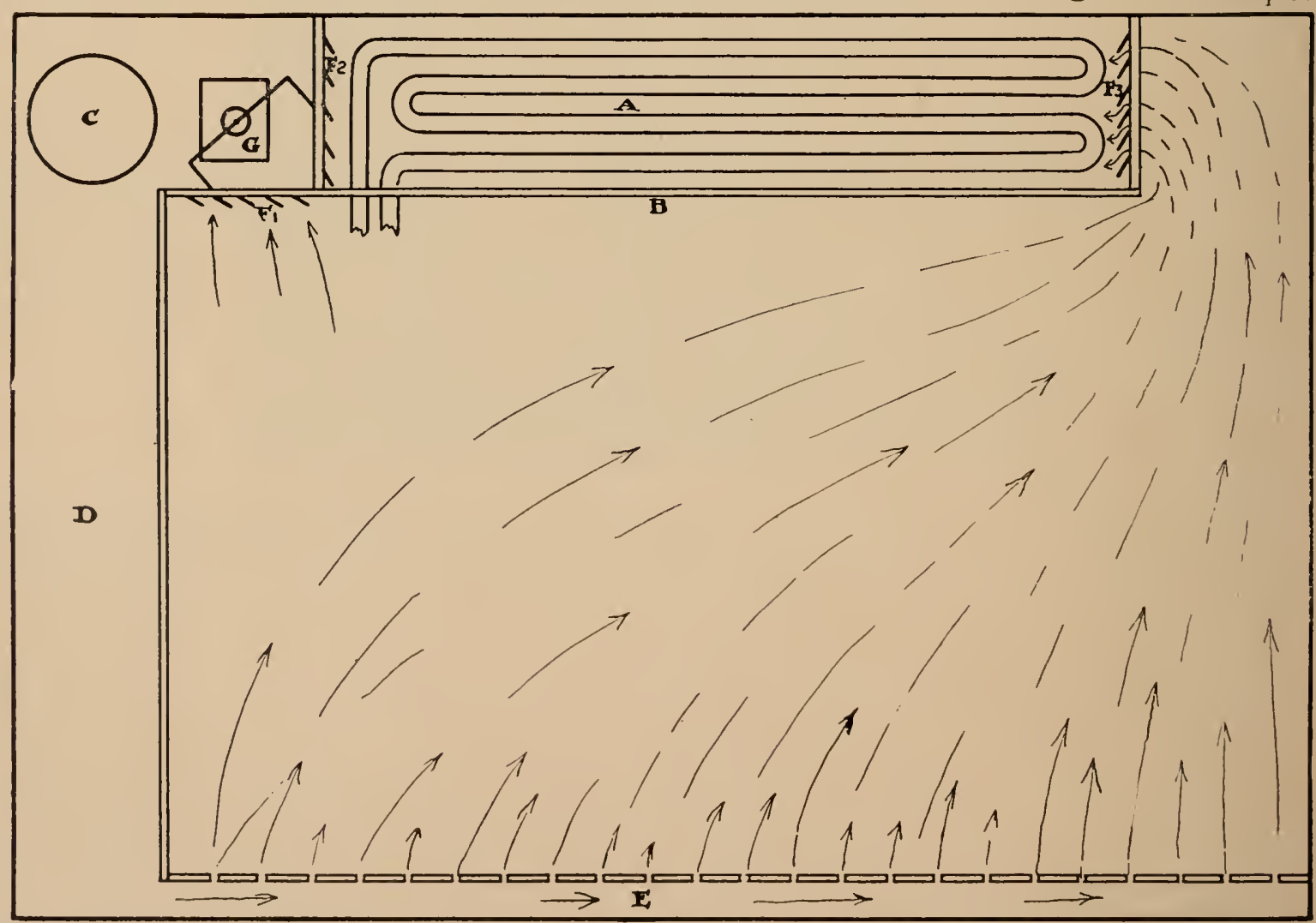

FIG. 9. Sectional diagram of precooler as designed and used at the Division of Horticulture, Central Experimental Farm, Ottawa.

The main advantage of precooling is to slow down the life processes as quickly as possible, thereby prolonging storage life. Another advantage, having questionable practicability of application, however, is distribution of the refrigera- 
tion load. This is accomplished by precooling the apples in a special room or chamber, before placing them in the storage room. In this way the refrigeration equipment in the storage room is not overloaded with field heat from the fruit.

At present, precoolers are based on the principle of heat extraction by the rapid movement of cold air over the product. Fig. 9 shows a vertical section of a precooling room used in conjunction with the experimental cold storage plant at Ottawa. The room containing approximately 2,000 cubic feet capacity has a cooling unit A made up of 400 feet of $1 \frac{1}{4}$-inch ammonia piping. The ammonia is fed by a thermo expansion valve to these pipes. This unit is enclosed by bunker B. Bunker temperature is controlled by a thermostat operating liquid and suction stop valves on unit $\mathrm{A}$. The fan $\mathrm{C}$ draws cooled air from this unit and delivers it at a rate of 6,000 C.F.M. via duct $D$ to the space $\mathrm{E}$ under a false floor. This floor is made of 2- by 4-inch lumber laid at right angles to the air flow. These 2 by 4's are spaced to leave a small slit between. The spacing is adjusted in such a way that a slight static pressure is built up in $\mathrm{E}$. This assures even distribution of cool air through all parts of the floor.

Temperature control of the room itself is carried out by modulating louvres $\mathrm{F}_{1}$ and $\mathrm{F}_{2}$, which are actuated by a thermostatically operated motor $\mathrm{G}$. When the precooler temperature is higher than the desired setting, air is drawn through the bunker $\mathrm{B}$ via louvre $\mathrm{F}_{2}$ and passes through the pre-described route. When the temperature approaches the desired point louvre $\mathrm{F}_{1}$ opens slightly and $\mathrm{F}_{2}$ closes to the same extent as $\mathrm{F}_{1}$ opens. If the temperature in the precooler continues to drop $F_{1}$ opens more and $F_{2}$ continues to close. This means that as the temperature drops an increasing percentage of the air is shortcircuited through $\mathrm{F}_{1}$ which is not cooled but is merely recirculated. Temperatures may be such that $\mathrm{F}_{2}$ is completely closed and $\mathrm{F}_{1}$ completely open, in which case all the air is recirculated. Maximum cooling effects can thus be derived from the cooling unit A without danger of the product freezing.

\section{Performance}

If a precooler of the foregoing type is used the rate of cooling of the apples will depend on two main factors; (1) type of package and (2) method of stowage. For maximum efficiency both factors should permit maximum heat removal from the apples.

Apples in a large package will not cool so quickly as those in smaller packages because in large packages a smaller percentage of the apples will be in contact with the walls of the container. Likewise, an open package will expose the apples to the air and thus bring about more rapid cooling than if the apples are in a completely closed package. The insulating properties of the container are also important. For example, corrugated paper-board containers of the same thickness as a wooden container would cool more slowly but this is not particularly significant when compared with the air protecting properties of the container. The most important consideration is to select containers that allow a maximum of air to come in contact with the fruit.

Proper stowage is important. If the containers are stowed directly on top of each other the cooled air coming from the floor can come in contact only with the sides of the container except, of course, for the bottom tier. If the containers are stowed too tightly, air flow again will be hampered. For maximum air contact, the packages should not be touching others alongside. Successive tiers should be built up so that each container is above the air space of the tier below.

$60847-3 \frac{1}{2}$ 
In Fig. 10 the actual performance of the precooler previously described in Fig. 9 can be seen. The maximum temperature represents the highest or slowest cooling fruit in the load and minimum is the lowest or fastest cooling points recorded. The fruit harvest temperature was $60^{\circ} \mathrm{F}$. and in slightly over 24 hours the mean temperature was down $40^{\circ} \mathrm{F}$, which means that rapid

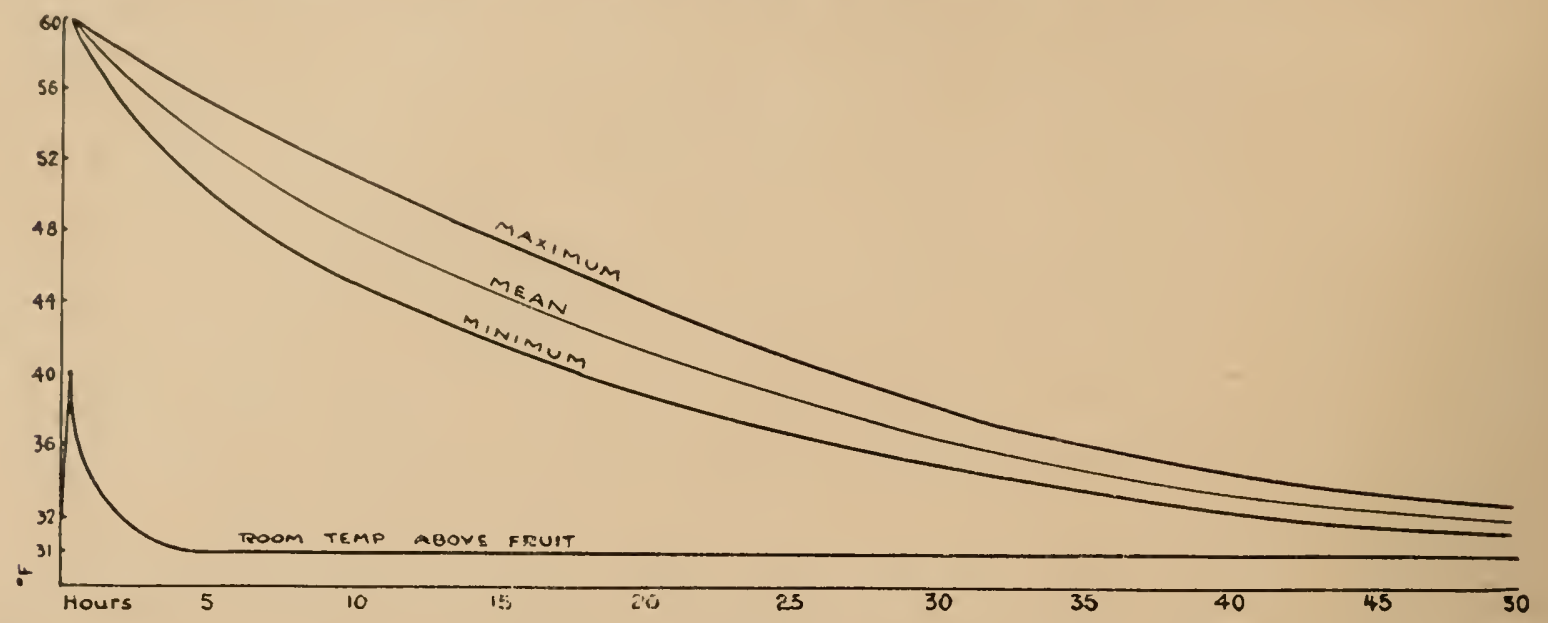

Fig. 10. Cooling rates of 200 bushels of Bartlett pears in precooler shown in Fig. 9. The temperature trends represent condition inside fruit at the centre of bushel hampers with top pads and liners.

high-temperature metabolism was practically reduced the first day. In 48 hours all the fruit was very close to the desired storage temperature of $32^{\circ} \mathrm{F}$. The fruit was then transferred to a $32^{\circ} \mathrm{F}$. storage temperature without any disturbance to the room temperature. In this manner maximum advantage of storage temperatures was obtained with a probable two to three weeks extension of storage life over what is usually considered "good" commercial storage conditions.

The rapid air circulation method of precooling should not be applied to holding in storage because the necessary rapid flow of dry air increases evaporation resulting in considerable drying of the product. If the temperatures are watched closely and the product removed as soon as the temperature is down, the resulting damage will be negligible in comparison with the advantages gained in rapid cooling.

\section{Precooling in Practice}

The system just described provides the most rapid form of heat removal by the use of air but it has disadvantages. Having a precooling chamber apart from the storage chamber means double handling and higher costs. Fruit has to be placed in the precooler upon arrival and later removed to the storage. This type of precooler has a place, however, where precooling is done previous to shipment. If it is near a railway siding the fruit can be delivered at one end and loaded into the railway car at the other. In this way cooling can be carried out before "spotting" the car and the handling is not increased over normal.

When precooling previous to storage, howerer, a compromise is usually made. This consists of precooling in the storage room itself, which requires extra cooling capacity. The forced air type of refrigeration lends itself to this modification for precooling and this is one of the reasons for its popularity. Rapid cooling in a precooling system is usually accomplished by two methods, (1) increasing air velocity; and (2) reducing the temperature of the air discharged from the cooler. 
In small chambers with short run ducts or no ducts at all air velocity can be increased with a variable speed motor or a speed reducing device on the fan. Air velocities that produce a complete change every 1 to 3 minutes can thus be used during the cooling. When the load is cooled the fan can be slowed to a normal change of air. Also during precooling the suction pressure can be reduced and the thermostat lowered to provide colder air. This. should be done with caution since air temperatures below $29^{\circ} \mathrm{F}$. are likely to damage the apples.

In storages that have two or more large rooms supplied from a common evaporator, excessive alteration of air movement may affect the air distribution. To avoid this condition the discharge air temperature may be lowered, taking into account the possibility of freezing apples. If carefully checked, air discharge temperatures of $29^{\circ} \mathrm{F}$. may be used safely, bringing the apple temperature down below $40^{\circ} \mathrm{F}$. in two to three days. When air flow rates have been changed and the rooms are used as normal storage chambers, the openings on the ducts should be checked and the dampers regulated to provide even air distribution under the slower air movement required for storage. Auxiliary forced air systems can also be installed in storages normally equipped with convection cooling.

When considering equipment for precooling, capacity is of the utmost importance. It is unfortunate that as much as six times the amount of refrigeration is required to cool the apples as is required to hold them at storage temperatures when cooled. It is poor policy to reduce the capacity below that required to cool the apples at the rate at which they are being loaded. As an example, the loading rate for a particular storage plant might average about. 200 bushels per day. The apple temperature under these conditions might. be $80^{\circ} \mathrm{F}$. This makes 8,000 pounds to be cooled from $80^{\circ} \mathrm{F}$. to $32^{\circ} \mathrm{F}$. every 24 hours during loading or a total of 8,000 (weight of fruit) $\times 48$ (degrees. reduction) $\times .9$ (specific heat of apples) $=345,600$ B.t.u. or approximately. $1 \cdot 2$ tons. This figure would be increased slightly by respiration and condensate: on cooling coils.

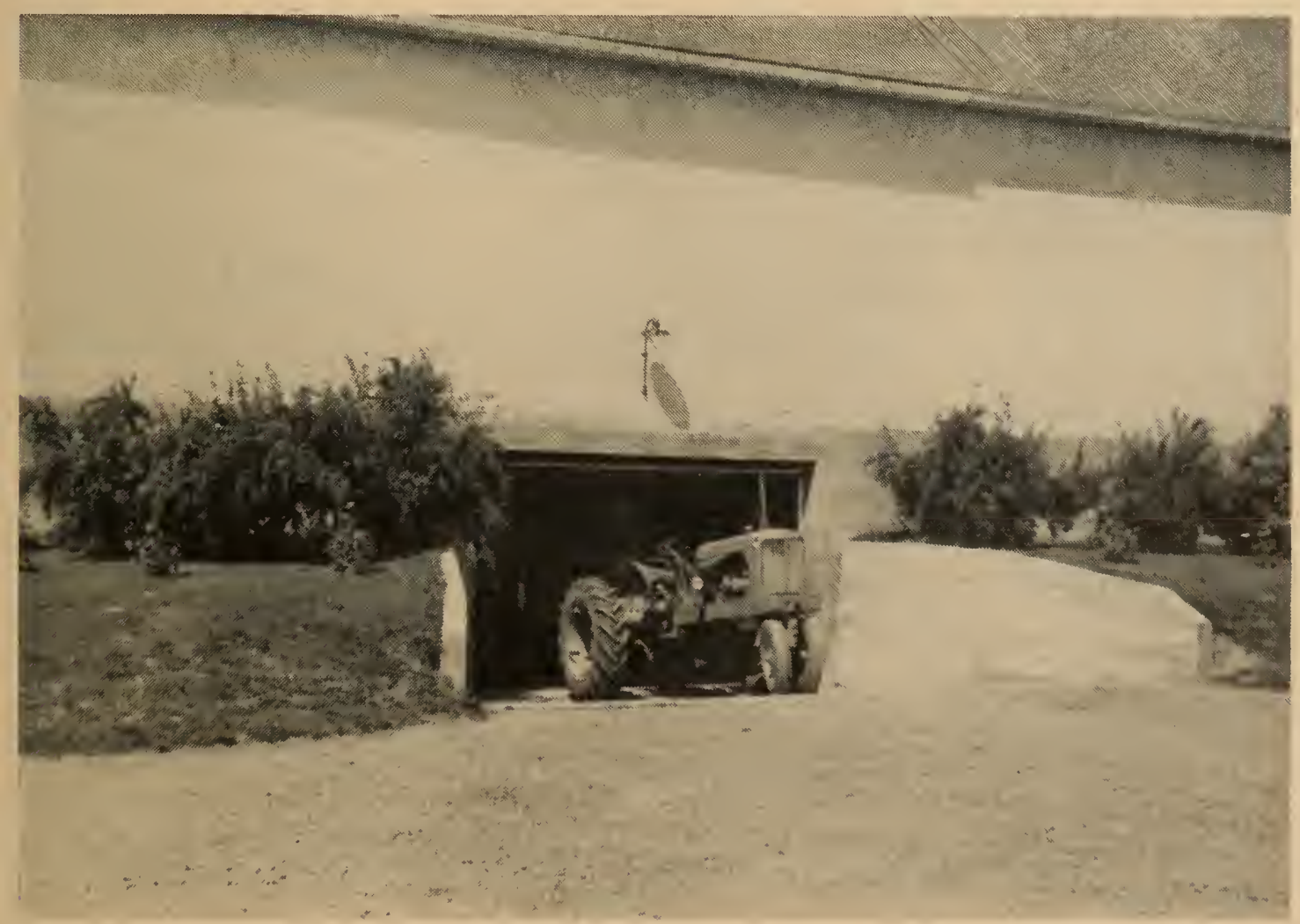

Frg. 11. Unloading fruit into storage. Accessibility saves valuable time during harest. 


\section{Storage Management}

Storage management involves more than just loading the apples into storage, cooling them to storage temperatures, and shipping them when required for market. For succesful operation, pre-storage factors such as orchard management and harvesting conditions as well as marketing practices must be considered.

\section{Nutritional}

Fertilizer treatment in the orchard, and particularly nitrogen, has an influence on the development of physiological disorders and many orchard and storage disorder's are known to be caused by nutritional disturbances. In gencral low vigour tends toward better storage behaviour, but it would be ridiculous to reduce crop and apple size and impair the health of the tree to this end. The nutritional program should therefore be a compromise between what is required for the well being of the tree and what will have the least detrimental effect on the storage behaviour of the apples.

Analyses have been made of the leaf tissues of McIntosh and Northern Spy varicties for nitrogen, phosphorous, potassium, and magnesium during the growing season. Later, observations were made on the storage behaviour of apples grown on these trees. It was found that when the level of nitrogen exceeded 2 per cent (dry weight basis) the storage quality was impaired. As a general rule the foliage analyses will exceed this value when applications are at or above the rate of $7 \frac{1}{2} \mathrm{lb}$. of ammonium sulphate or $15 \mathrm{lb}$. of a 9-5-7 fertilizer per fully mature tree (30 years). Phosphorus was found to have little or no effect on storage behaviour. The effect of potassium appeared to be related to the ratio between it and nitrogen. The greater the nitrogen potassium ratio, the poorer was the quality and storage behaviour of the apples. $(\mathrm{N} / \mathrm{K}$ over 1.25 appeared to reduce quality.) Analysis of leaf samples is a good guide to fertilizer practice.

\section{Size of Crop}

In general a small crop on a tree that is making rapid growth tends to have poor keeping quality. On the other hand, poor growth may produce heavy crops of small apples that may have good storage properties but will be undesirable for marketing. The age of the tree will influence keeping properties also. Fruit from young trees is more susceptible to core flush, bitter pit, and breakdown. It is therefore good storage practice to market apples from young trees as quickly as possible. The heavier the thinning the greater is the ratio between foliage and fruit, rcsulting in a lessening of storage life. Pruning has a similar effect on storage behaviour.

\section{Climatic Factors}

The influence of climate and weather is complex but experiments indicate that extremes in any direction are likely to be harmful. The only precaution that can be taken is to maintain a careful watch on apples in storage when weather conditions, particularly at or near harvest, have deviated from normal.

\section{Harvesting Maturity}

No method of determining correct harvest maturity is infallible. The grower will harvest his fruit when in his own judgment it is ready, taking into account volume of crop, labour conditions, etc. The various tests will be helpful only in confirming his own opinions or as a guide when in doubt. The storage operator on the other hand can use maturity tests as an aid in grading apples as immature, mature, and over-mature. If these categories are segregated in storage, the 
poorer keeping types can be marketed early and the others held for longer storage. In general immature apples tend to shrivel in storage and do not develop full colour or flavour. If allowed to mature on the tree, the fruit will be fully coloured and develop a highly aromatic flavour in storage.

Harvesting at the proper stage of maturity is extremely important for other reasons. Delayed harvesting may result in excessive dropping, frost damage, or over-mature apples. Harvesting McIntosh a week to ten days earlier than optimum has been known to double the amount of core flush found at the end of storage. Bitter pit, although not associated with maturity, can be more readily eliminated if the crop is allowed to mature on the tree. On the other hand some disorders, such as deep scald and senile breakdown, may be increased by delayed harvest.

Since apples are living material, most methods for determining maturity are based on critical physiological processes. Chief of these is respiration, as indicated by carbon dioxide output. In spite of many attempts to find a simpler and more practical method, no other reliable substitute has yet been found. There are, however, several ways by which maturity can be "approximately" measured.

Ground Colour:-The change in colour from green to yellow, on the unblushed portion of the apple skin, has long been used as a maturity guide. Colour charts against which the apples may be matched have been prepared by the Division of Horticulture, and are available for McIntosh and Fameuse varieties. In exceptional seasons, and under certain orchard conditions, the chart is unreliable but it is nevertheless one of the most satisfactory maturity guides for these varieties in Eastern Canada.

Starch Tests:-As apples approach maturity on the tree the reserve starch is changed to sugars. A simple test for maturity based on this fact can be made by cutting an apple in half across the core and immersing the exposed sections in $\frac{1}{4}$ inch of potassium iodide solution for one minute. The areas containing starch are revealed by a blue black colour in contrast to the normal white tissue of the non-starch area. A light rinse with water will make the starch pattern clearer. The starch disappears in the core area first (see Fig. 12) and finally from the area next the skin. In making this test ten apples at least, picked at random, should be used and the average pattern compared with the chart to determine the stage of maturity. Different varieties show different patterns-two typical examples are shown in Fig. 12.

The iodine solution for this test is made up as follows:

Dissolve 10 grams (about $\frac{1}{3}$ ounce) of potassium iodide in 1 quart of water. When properly dissolved add $2 \cdot 5$ grams (about $1 / 12$ ounce) of iodine crystals. If the iodine is heated over a flame until it flows, it will dissolve in the potassium iodide solution much more readily. This solution should be kept in a dark coloured bottle and away from light when not in use.

For high quality storage most of the earlier varieties (up to and including the McIntosh season) should reach or exceed stage 4 . Recent information indicates that McIntosh are inclined to drop when stage 7, on the lower chart, is reached. The starch test is not very satisfactory for later varieties because most of these show very little starch loss at harvest (stages 1 or 2). In using this test it should be noted that the starch pattern will vary during the day. It is possible also that weather conditions during the day may influence the starch pattern. For that reason, the test should be made during the forenoon. Like the ground-colour test the starch test may not always be reliable in itself. 
Pressure Test:-This test is made by measuring the force required to push a plunger of standard size into the flesh of an apple. The test is based on the fact that the apple tissue becomes softer as it matures, but unfortunately,

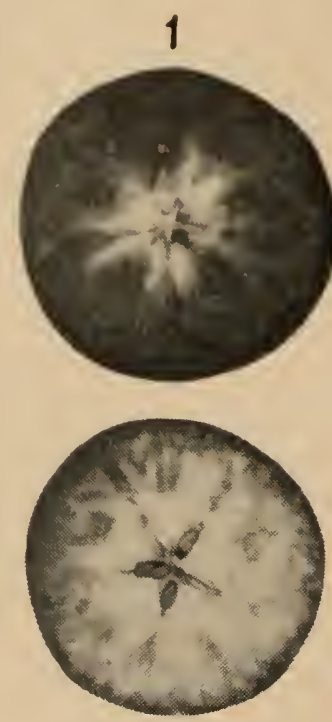

4

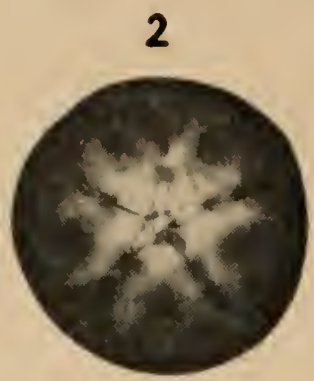

3

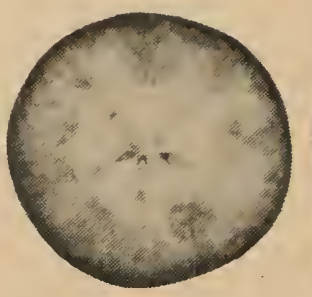

5
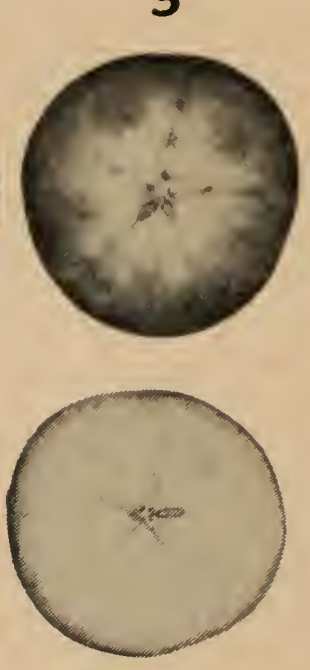

6

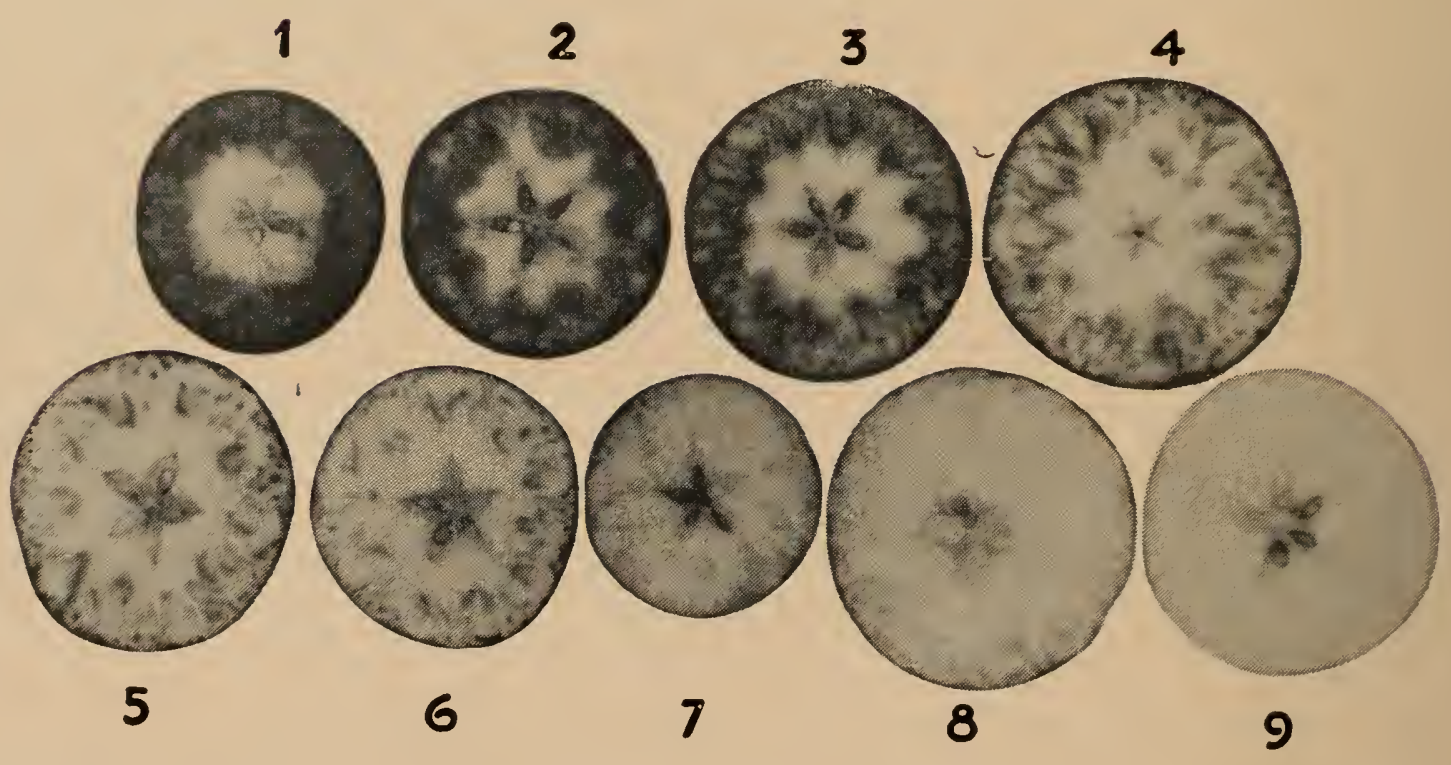

Fig. 12. Starch pattern in apples at harvest. Upper, Ottawa seedling 0-2016, lower, M[cIntosh. such changes in tissue are so insignificant that the test is not reliable. Another factor is that there is a considerable variation in firmness in different portions of the same apple. Seasonal and other variations also contribute to its inaccuracy.

Other Tests:- Seed colour and ease of separation from the stem are frequently used as maturity guides. Experimental work indicates that these are only very rough indications. Most growers usually check for apple drop and ease of separation from the tree as a precautionary measure.

\section{Handling}

Unfortunately, between harvest and consumption, apples must be picked, lifted on and off a truck en route to the packing shed, graded, packed, and transported to and around the storage. Every time an apple is handled it is likely to be bruised, therefore as much care as is consistent with getting the crop through storage and to the market should be exercised. Close observation 
of the apples themselves will be the best guide to the necessary corrective measures. The average operator does not realize that even a slight bruise will increase in size in storage. The greatest damage however, is from secondary effects, such as breakdown and rots. Recently experiments along these lines have indicated that even moderately rough handling of McIntosh will cause an increase of 35 per cent wastage by rots at the end of storage life (mid-February). The amount of senile breakdown at about the same time was as follows:

Very careful handling .............. 5 per cent

Slight bruising ................ 10 per cent

Moderately rough handling ........... 30 per cent

The "very careful handling" here represented is not practical, but it is important to remember that the onset of other disorders increases with the amount of bruising.

\section{Grading}

The choice of grader depends on the accommodation, type of pack, and local preference. The main requirements of a grader are fast and efficient sizing in accordance with the pack and a minimal amount of injury to the apples.

When to grade and pack is a problem that concerns many storage operators. Grading before storage has the following advantages: (1) It avoids using valuable storage space for below-grade fruit; (2) stowage and handling in storage are facilitated; (3) grading early is less likely to injure apples by bruising; and (4) storage inventories are facilitated. Grading during storage also has many advantages, some of which are as follows: (1) delays in placing apples in storage because of grading are avoided; (2) disorders that develop after storage can be eliminated from the pack; (3) labour distribution is more efficient; (4) fewer packers and graders are required; and (5) less grading equipment and fewer facilities are required.

Although both methods have advantages, grading during storage is considered preferable. If, however, the crop has a high proportion of unmarketable apples it should be graded before storage to save valuable space. Although apples are less liable to bruising early in storage than later in the storage period, early grading is usually done under pressure, resulting in rough handling. Moreover, with McIntosh apples, at least, the secondary effects of bruising are not particularly serious unless bruising occurs after the end of Dccember. Thus, grading during storage contributes to better organization and provides the consumer with a more consistently high quality product. The previous discussion applies to scald-free varieties. Where scald is a factor, as with Wagener, oil-paper wrapping has to be done before storage.

\section{Storage Conditions}

The storage life of apples depends not only on the maturity and quality of the crop and the conditions under which it was grown, but also on storage conditions and management. Since apples are living material a knowledge of physiological processes is fundamental to understanding storage behaviour. Among the important factors are respiration rates and trends, as measured by the production of carbon dioxide. 


\section{Respiration Data}

Fig. 13 shows the rate at which McIntosh apples respire under ordinary temperature conditions during the three phases, growing, maturing, and storage. If MeIntosh apples are harvested in phase 1 the ground colour will be rery green, the apples will shrivel in storage, and fail to mature normally. If harvested at the beginning of phase 2, similar but slightly improved results will be obtained. The best results, however, can be obtained at the end of phase 2. It is at this point that rapid changes from green to yellow ground colour are noted.

There appears to be a definite change in the type of metabolism from the maturing phase to the storage phase. This conclusion has been reached from observations of MeIntosh apples under various circumstances. If apples are harrested in the maturing phase (maturing phase, Fig. 13) and are cooled immediately to $32^{\circ} \mathrm{F}$., core flush is almost certain to develop. Likewise, exposure to methyl bromide in this phase is more likely to produce injury. Even in gas storage carbon dioxide injury is much more likely to occur in this phase. By allowing the apples to pass into the storage phase (storage phase 3, Fig. 13) the previously mentioned troubles are eliminated.

Actually the best time to harvest is at or slightly after the critical point marked on Fig. 13. The small remaining portion of the maturing phase will then be finished before the temperature of the apples is reduced to that of the storage $\left(32^{\circ} \mathrm{F}\right.$.). The colour chart prepared by the Division of Horticulture was designed so that the fruit grower could determine this point for himself.

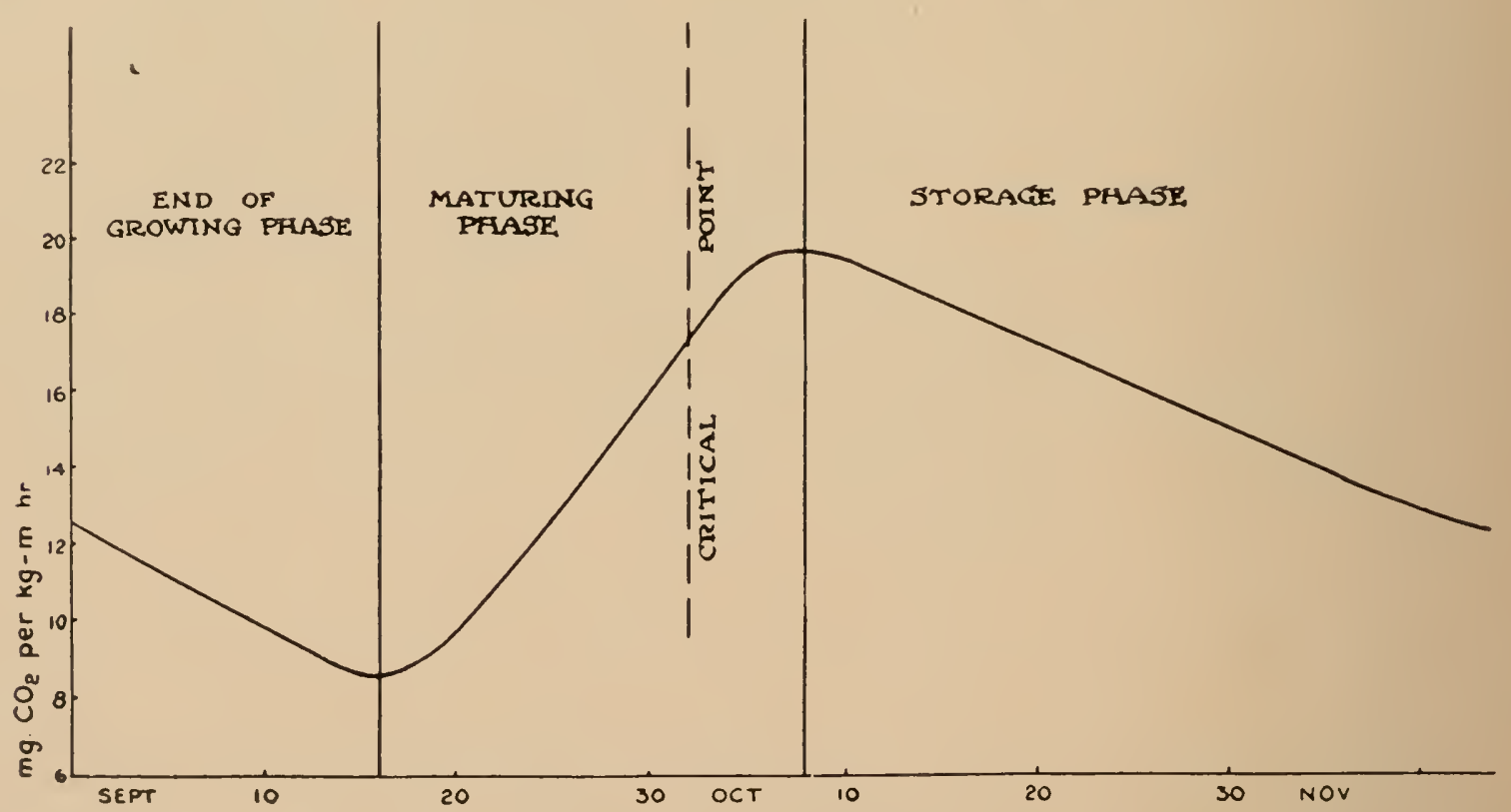

FIG. 13. Trend of respiration in McIntosh apples throughout the harvesting period. Note the critical point near the end of September. For highest quality this point should be reached before harvest.

\section{Effect of Temperature}

After the apples are placed in storage, respiration rates show a gradual decline. (Fig. 13, storage phase.) When the temperature of the apples is reduced this decline is not so steep and the rates are not so great. This means that the approach to senility is delayed by the conservation of food elements within the cells. This is illustrated in Fig. 14. It will be noted from this graph that as temperature is increased, the respiration rate is also increased. Another important point is that although reductions in respiration rates are obtained 
all the way from higher temperature down to $32^{\circ} \mathrm{F}$, a reduction is not so great when the temperature approaches $35^{\circ} \mathrm{F}$. It is therefore important to reduce the apple temperature to this point as rapidly as possible.

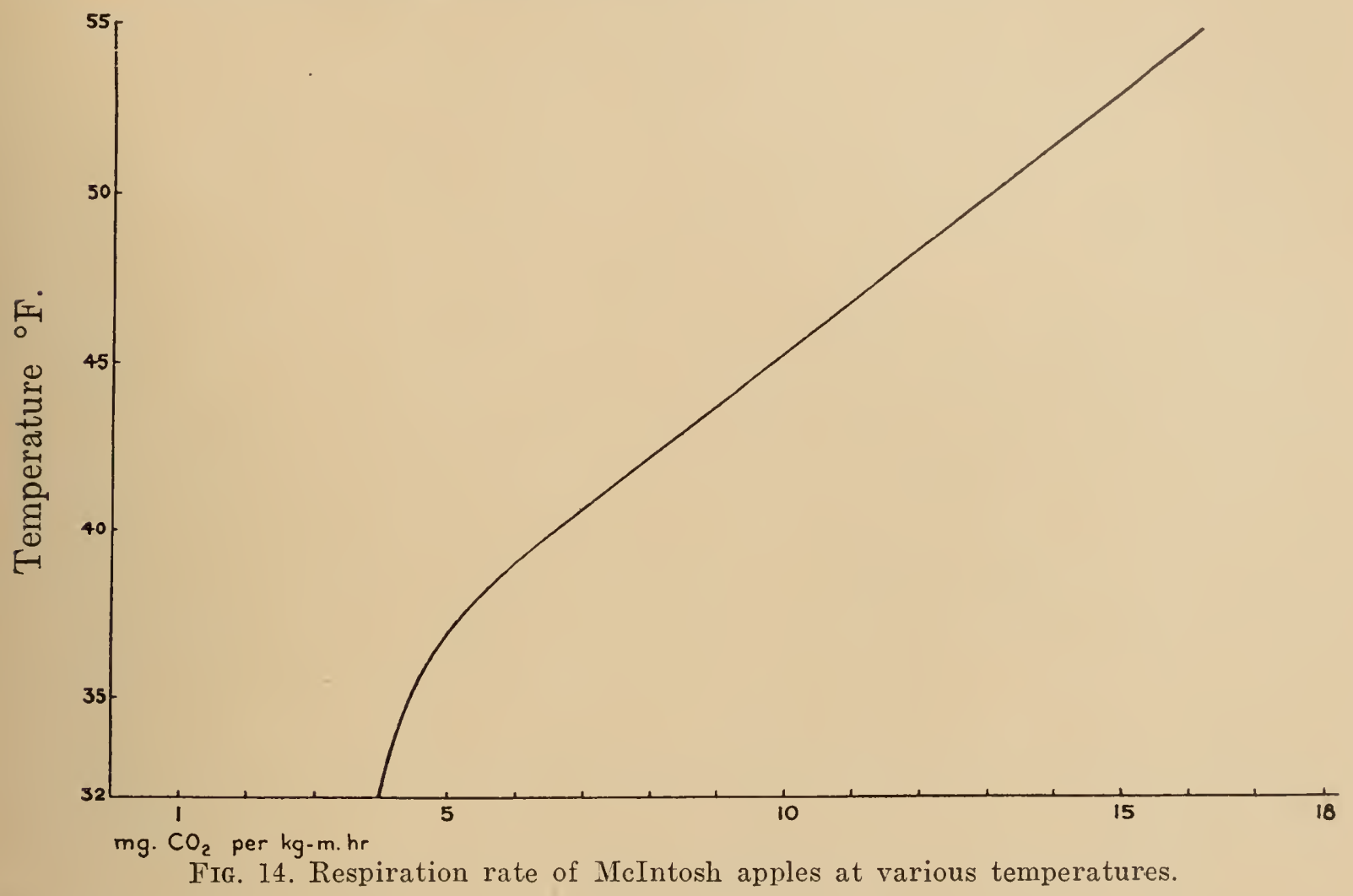

The storage operator, however, measures storage life by the length of time that apples can be held in a marketable condition. The determining factors that affect marketability are loss of quality and the onset of disorders either physiological or pathological. The former is frequently neglected and many apples are sold that have lost all semblance of flavour but may be otherwise sound.

\section{Measuring Quality}

It is difficult to assess quality satisfactorily. Since the only known method is to taste the fruit, and since tastes differ widely, some criterion must be established. To this end a score sheet has been devised which, if applied with discretion by an experienced taster, provides a reliable index of quality. This score has three main factors, flavour, texture, and appearance, collectively providing for a maximum score of 90 points. A miscellaneous category is also provided, giving an additional 9 points for certain external characteristics associated with storage, such as hardness (to feel), greasiness, and ground colour. High aroma with moderate acidity and sweetness are required for maximum flavour score (30 points). The score is graded downwards according to the loss of these properties to a sweet insipid flavour associated with senility. The maximum score (30 points) is given for a crisp, firm texture, grading down through soft textures to ultimate mealiness. Appearance is rated on quality and extent of colour, with the maximum score (30 points) given for apples having what is considered the ideal for the variety.

When making a quality evaluation, the storage operator should allow about one week ripening period at $60^{\circ} \mathrm{F}$. after removal from storage. This will approximate the quality of the apple when it reaches the consumer. Fig. 15 represents the trend of scores for McIntosh apples calculated on this basis. 
When considering the gencral quality trends in Fig. 15 it will be noted that the $32^{\circ} \mathrm{F}$. ('urve takes a different trend than does the $36^{\circ} \mathrm{F}$. or $39^{\circ} \mathrm{F}$. curves. At no time does quality reach the maximum at $32^{\circ} \mathrm{F}$. Highest quality is reached during Decenber which shows a gradual decline to level ralues. This is mantained well into February, after which a rapid falling

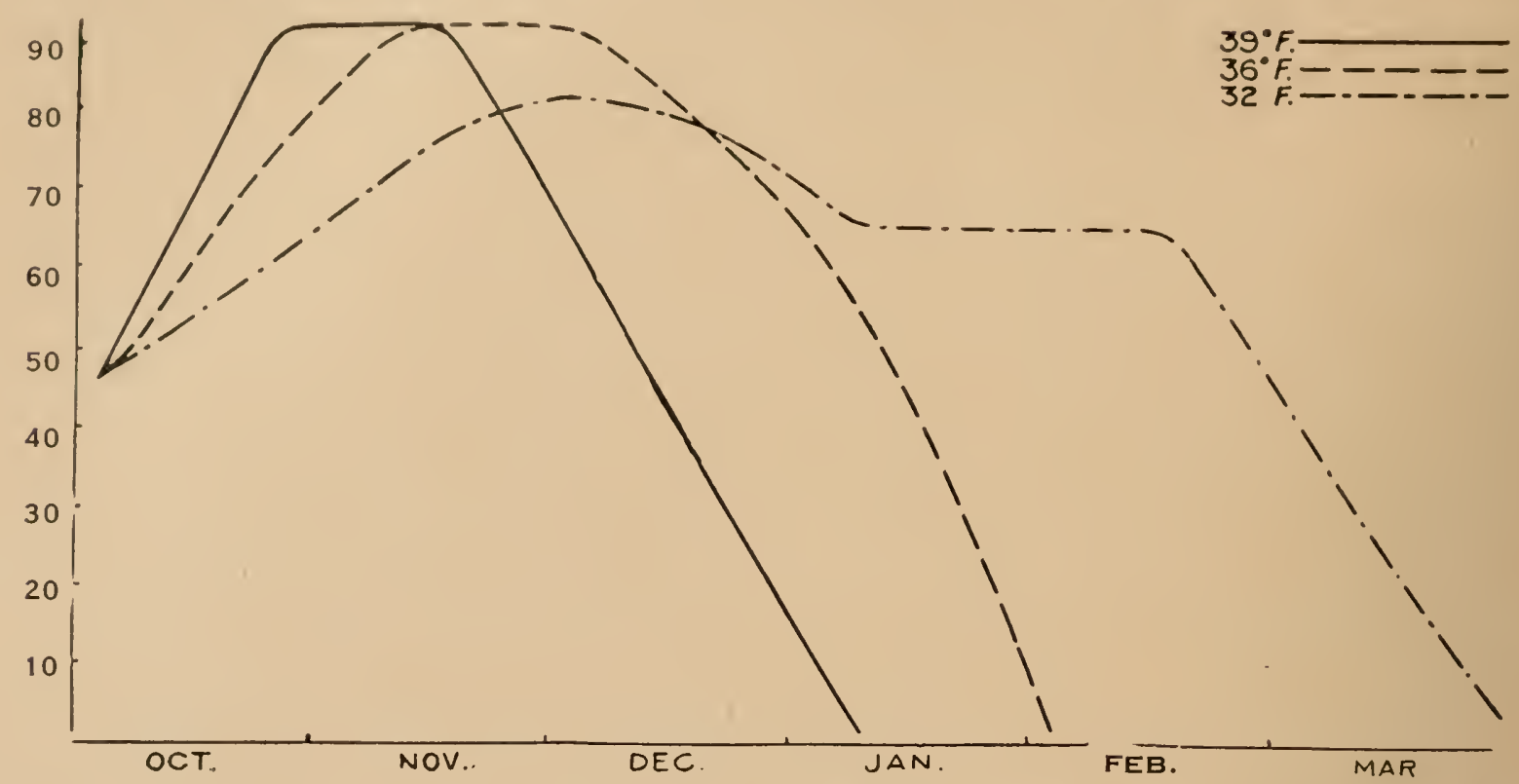

FIG. 15. Approximate trend of eating quality of McIntosh apples at three different storage temperatures. (Maximum quality 100.)

off is noted. At $36^{\circ} \mathrm{F}$. and $39^{\circ} \mathrm{F}$. a more rapid progress towards a maximum is seen. This is maintained for a relatively short period after which a rapid drop in quality is noted.

The end of storage life so far as quality is concerned should be at the point where quality values show a rapid drop. This point for each temperature is as follows:

$39^{\circ} \mathrm{F}$. end of November-middle of December

$36^{\circ} \mathrm{F}$. first week of December-middle of January

$32^{\circ} \mathrm{F}$. middle of February-first of March

It must be kept in mind, however, that these points will be influenced by pre-storage factors, method of storage, type of containers, etc. Furthermore, although this marks the end of storage life as governed by quality, the apples may still have an excellent appearance and it is unfortunate that such apples are marketed. So far as other varieties are concerned it is probable that quality trends will assume a similar form, the chief difference, of course, being the time factor. It must also be remembered that varieties which normally possess stronger flavours can afford to lose much more quality before becoming objectionable.

\section{Storage Atmosphere}

The main factor to be considered in storage is temperature, but other factors also are important. The storage room forms the environment for the apple for several months or more and such things as humidity and other atmospheric conditions are just as important during storage as they were during growth in the orchard. 
Humidity:-When water evaporates, it changes from a liquid to a gas and passes into the atmosphere. Since apples are composed largely of water (over 80 per cent usually) and are relatively porous, evaporation causes considerable loss in quality, weight, and to some extent rolume.

To control this loss the humidity of the air must be maintained at as high a level as possible. Once the air reaches a certain level of saturation evaporation ceases. Thus if apples are placed in a relatively well sealed room, the humidity of the air will rise to a level where evaporation ceases and if maintained at this point the moisture in the apple will remain almost constant, which is the objective of an ideal apple storage.

It is difficult to maintain the storage atmosphere at such a high level of humidity, since refrigeration pipes or other cold surfaces act as condensation points. This is illustrated in Fig. 16 using as an example apples at $35^{\circ} \mathrm{F}$. (a point during the cooling cycle) with cooling coils at $20^{\circ} \mathrm{F}$. The air which may be slightly over $35^{\circ} \mathrm{F}$. in some areas of the storage room is very nearly saturated with evaporated moisture from the apples. This air rises and contact with the cooling coils lowers its temperature to considerably below $35^{\circ} \mathrm{F}$. The ability of the air to hold water is thus reduced and the moisture condenses on the cooling coils. The cooled air eventually returns to the apple, picking up more moisture. This is, in effect, a dehydration process in which the air currents carry moisture from the apple to the refrigeration coil.

Insulation.-Dehydration may be controlled by several means: Insulation is the most important of these since it prevents cold walls and ceiling surfaces and reduces the need for refrigeration.

Refrigeration.-The higher the cooling surface temperature, the less condensation takes place. Similarly, the shorter time the cooling surface is in operation, the less will be the condensation. (See earlier discussion on suction pressure, control valves, etc.)

Precooling.-The moisture loss from cold apples is not so great as from warm apples. Rapid cooling thus prevents moisture loss by $(a)$ less evaporation and $(b)$ decreasing the refrigeration load.

Measuring Relative Humidity.-Instruments based on temperature reduction by water evaporation are usually used for measuring relative humidity. This is done by having two thermometers that are very carefully matched with regard to temperature reading. Moisture is permitted to evaporate from the surface of the bulb of one thermometer and the other remains dry. This instrument is known as a wet and dry bulb thermometer. The drier the air the more rapidly the water will evaporate from the wet bulb of the thermometer and thus bring about a reduction in temperature below that of the dry bulb. By consulting a chart usually supplied with the instrument the relative humidity can be determined by knowing the wet and dry bulb temperatures. To obtain accurate temperature readings the air flow over these bulbs must be fairly rapid. This is effected by swinging the thermometers in a circular motion. as with the sling psychrometer (sce Fig. 17) or forcing air over the thermometer bulbs as in the hand-aspirated psychrometer. The latter is usually more satisfactory, particularly because it is not so likely to be damaged in operation as the sling psychrometer. Both are fairly satisfactory when readings within 2 to 3 per cent accuracy are required.

Other devices are used for indicating relative humidity, such as the ordinary wet and dry bulb thermometer, the hair hygrometer, the dew-point apparatus and others. However, it has been found that the hand-aspirated or the sling psychrometer of reliable manufacture are the most practical and reliable. For arerage commercial apple storage it has been found that 90 per 
cent relative humidity is satisfactory. Under ordinary circumstances a moderately well filled storage room will reach this point if the temperature control is reasonably good and there is no appreciable moisture loss.

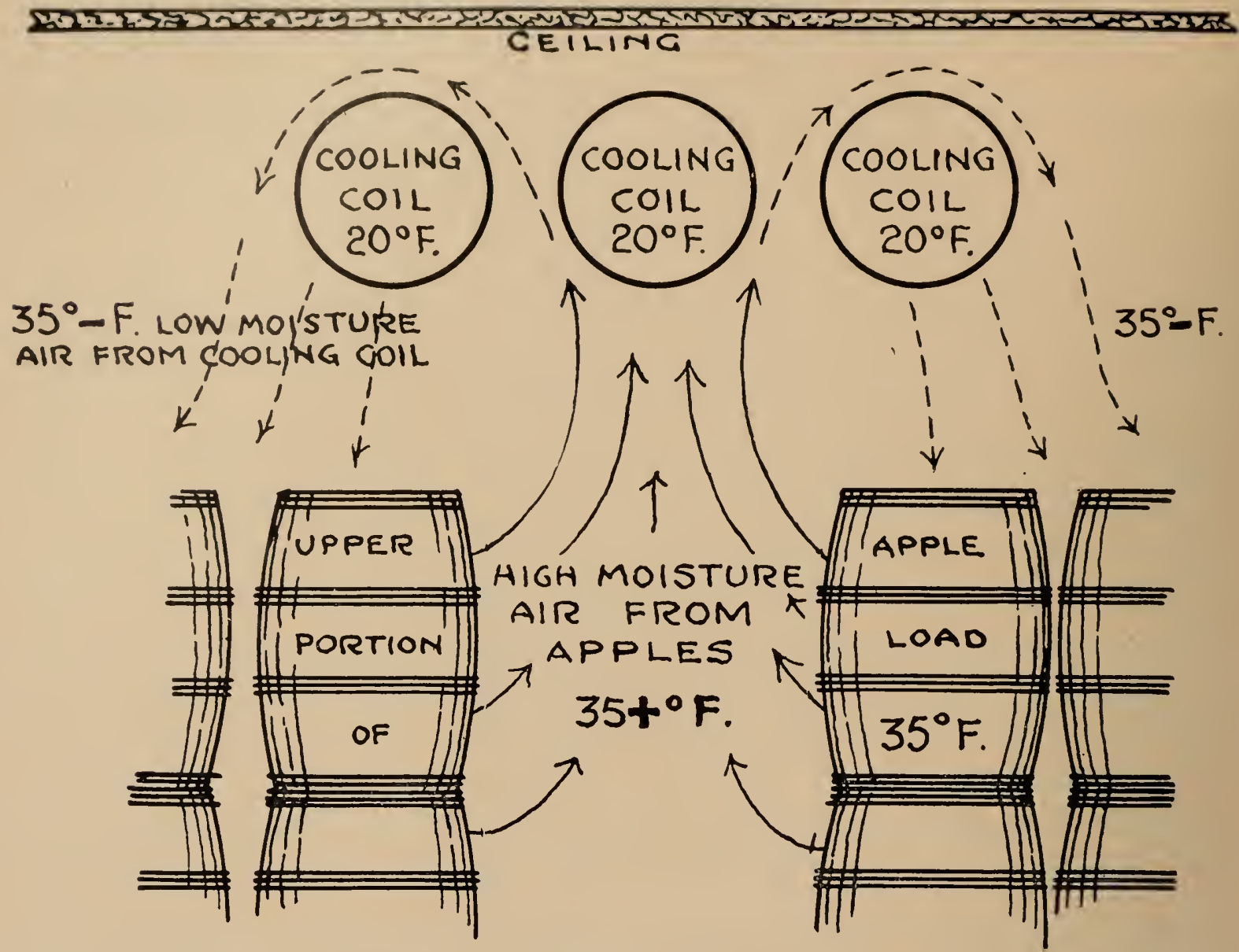

Fig. 16. Diagrammatic illustration showing the principle of moisture loss on cooling pipes in storage.

Other Gaseous Components.-In addition to moisture, apples give off carbon dioxide in fairly large amounts and a great number of chemical compounds, classified as volatiles, in minute quantities. The carbon dioxide found in storage rooms is seldom high enough to be harmful. The volatiles on the other hand are harmful. These volatiles, as far as is known, are produced when the apple approaches the eating ripe stage. Although they are responsible for the aromatic eating characteristics of the apple, they also increase the ripening rate and cause certain physiological disorders.

Ventilation will remove volatiles, but it is expensive because it increases the refrigeration load, and detrimental because it removes moisture. Since oil has great absorptive properties, oil wraps or shredded oil paper may be used very effectively for the control of superficial scald by removing volatiles. Unfortunately, this procedure is not effective for the removal of all volatiles. Furthermore, wrapping, which is more effective than shredded paper, is a costly and laborious procedure. Activated charcoal air filtration is another means of controlling volatiles. It delays senile breakdown; improves quality development and retention; and delays softening, as indicated by soluble pectin content. Storage room odours and taints are also reduced. The method employed is to circulate the storage room air through a bed of charcoal with a fan. Activated cocoanut shell charcoal is the most satisfactory. The activation process consists of heat treatment, which makes the particles more porous and thus increases the absorptive properties manyfold. To permit absorption of the volatiles the flow of air through the charcoal should be kept to about 60 lineal feet 
per minute. The charcoal bed should be $\frac{3}{8}$ inches thick but it is felt that a greater depth would be advantageous. The charcoal should be uniform throughout so that an even flow will pass through the filter at all points. Favourable

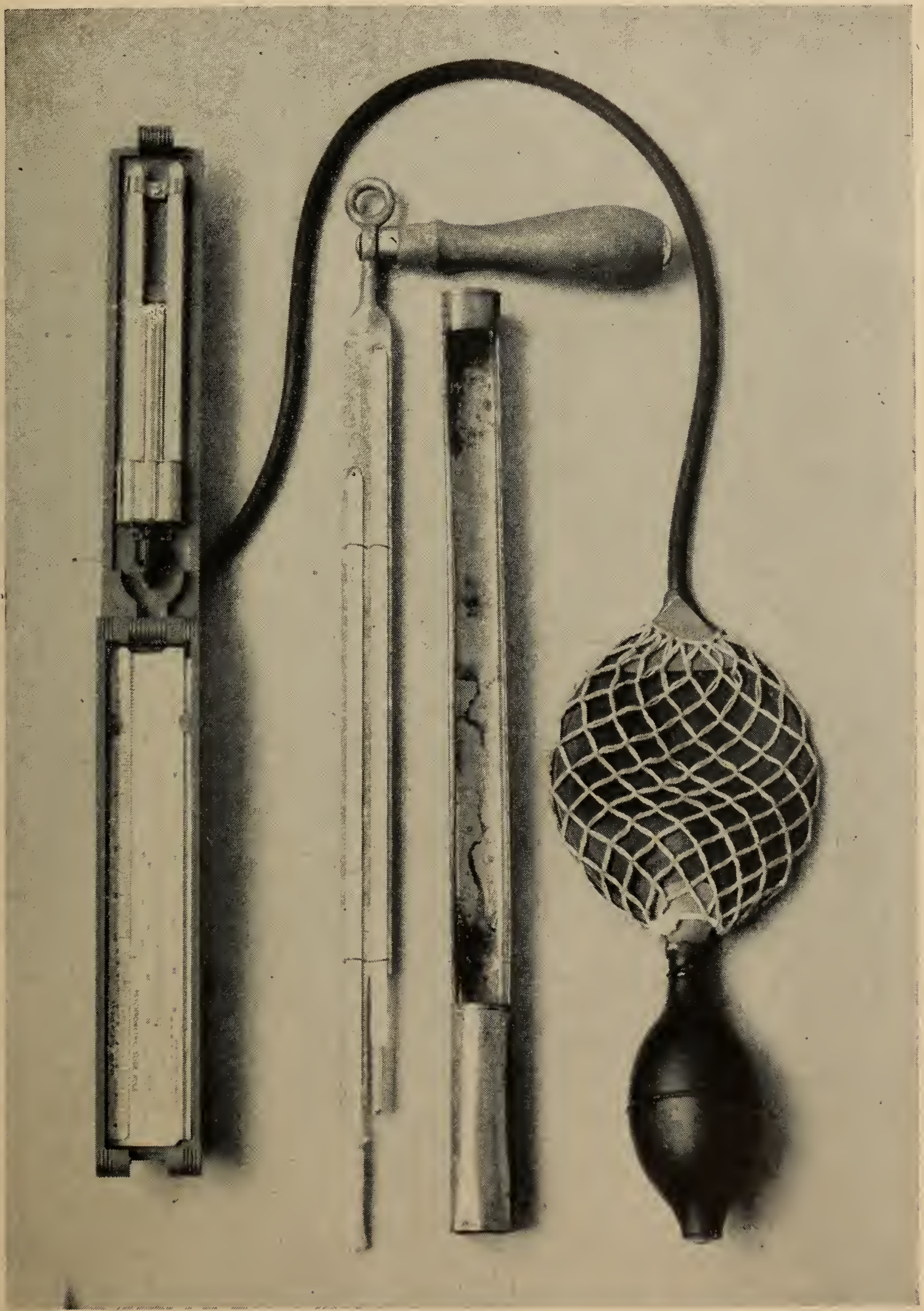

Fia. 17. Wet and dry bulb instruments for determining relative humidity. On left is hand aspirated type with squeeze bulb attached. In centre is sling psychrometer type.

results have been obtained by using one set of filters throughout the season, but there is reason to believe that frequent changes would increase the effectiveness of the system. 


\section{Fungal Rots}

\section{Storage Disorders}

As distinguished from physiological disorder's, fungi are organisms that actually attack the apples. They probably cause more waste in storage than any other single factor, and in adranced stages form a fuzzy growth, which may be blue, grey or some other colour, on the decayed portion of the fruit. Careful handling to prevent skin damage is one of the most effective methods of preventing fungal lots. since apples become less resistant to fungal attack as they approach scnility, marketing before advanced maturity is also a means of preventing loss.

\section{Core Flush (Core Browning)}

Core flush occurs in many varieties and may be caused by different factors. In McIntosh it is usually more prevalent at $32^{\circ} \mathrm{F}$. than at temperatures near $40^{\circ} \mathrm{F}$., whereas in Famcuse, the reverse is true. It rarely appears much before the quality of the apples falls off. As mentioned previously, young orchards, and orchards fed excessive amounts of nitrogen are more likely to produce susceptible apples. Since apples in certain districts are more likely to have core flush than others, it is possible that climatic factors may be partly responsible. Core flush may be confused with corky core, a disorder caused by boron deficiency, but the storage operator in consultation with the orchardist should be able to identify disorders of the corky type.

\section{Senile Breakdown (Mealy Breakdown)}

Senility may be caused by lack of rapid cooling at harvest, too high temperatures during storage, or by harvesting over-mature apples. Rough handling or bruising will also hasten the onset of senility in storage as will excessively warm weather at harvest. The presence of senile breakdown indicates that the apples are no longer marketable.

\section{Soft Scald (Low Temperature Breakdown or Deep Scald)}

This disorder and other forms of low-temperature breakdown (soggy breakdown) are relatively unimportant. As the name implies, they occur at lower storage temperatures $\left(32^{\circ}\right.$ to $36^{\circ} \mathrm{F}$.). They should not be confused with freezing injury which can be caused only by actual freezing of the tissues $\left(29^{\circ} \mathrm{F}\right.$. and lower). Wealthy, Jonathan, Grimes Golden, Cox Orange, and Ribston are varieties on which low temperature disorders may appear. On the other hand they have been found so rarely on Northern Spy and McIntosh that it is not worth while considering temperature adjustment to correct them. Apple boxes made from freshly cut cedar have been known to cause a disorder very similar to soft scald, and this may be true of other woods also. Allowing the boxes to cure for several months before storage appears to be a satisfactory preventive measure.

\section{Superficial Scald}

Most varieties suffer from this disorder, but in the blushed varieties it is usually so inconspicuous that it can be regarded as unimportant. McIntosh and other blushed varieties may, however, be scriously affected if the blush is of poor quality because of too much nitrogen or too carly harresting. Under gas storage scald may also be serious. When scald is expected from these causes such susceptible varieties as Rhode Island Greening, Wagener, and Yellow Newtown should be wrapped with wrappers containing odourless mineral oil. 
Although not so effective, shredded oil paper can also be used. The early part of storage is the most critical; therefore, control measures should begin at the time of storage and continue throughout.

\section{Lenticel Spotting}

There are many causes for this disorder. Fundamentally, however, it is caused by injury to the tissues around the lenticel by virtue of substances (mostly gases) gaining entrance. Ammonia refrigerant, ethylene, and acetaldehyde have been known to be causal factors. A fer varieties, such as Linda, may develop this disorder in spite of any known precautions. The only preventive measure for these varieties is to market the apples before the disorder develops. The most common cause in McIntosh and most other varicties is placing over-mature apples in the same storage room. The over-mature apples give off ethylene and other gases that cause lenticel spotting in the less mature apples. A whole storage room of sound McIntosh may be almost ruined by placing over-mature fruit in the same room.

\section{Other Disorders}

Such disorders as water core, bitter pit, etc., frequently found in storage are not true storage disorders since rarely are they found on apples not affected previous to storage. They may increase in intensity during storage, however.

\section{Controlled Atmosphere Storage (Gas Storage)}

In this type of storage a higher concentration of carbon dioxide and a lower concentration of oxygen than is normally found in air for the preservation of fruits is used, generally in combination with refrigeration or low temperatures. Apples normally give off carbon dioxide and take in oxygen and if these processes can be slowed down, as happens in low temperature storage, life is prolonged. Increased carbon dioxide and reduced oxygen have an effect similar to that of temperature reduction. Like temperature, however, these conditions must be controlled. In this method the fruit is enclosed in a gastight refrigerated room fitted with an apparatus that determines the concentration of gases and a simple, controlled, ventilating device. Daily determinations of carbon dioxide and occasionally of oxygen content are made. When the concentration of these gases reaches the prescribed point for the variety of fruit involved, rentilation is carried out by starting a small fan.

\section{Advantages of Controlled Atmosphere Storage}

The prolongation of storage life is one of the important advantages of controlled atmosphere storage. McIntosh apples were removed from gas storage at $39^{\circ} \mathrm{F}$. in February in prime condition, although November is the latest month to which prime conditions can be maintained in ordinary storage at this temperature. Furthermore, maximum quality can be attained which is not usual for lower temperature storage.

Physiological disorders associated with low temperatures also can be controlled without a reduction in storage life. For example, it has been difficult to hold Cox Orange Pippin at $32^{\circ} \mathrm{F}$. until the end of December without inducing low-temperature breakdown (at higher temperatures the storage life is comparatively short). This variety has been successfully stored at $39^{\circ} \mathrm{F}$. under controlled atmosphere well into January without low-temperature breakdown and with little loss in quality. Practically complete control of core flush in McIntosh may be attained in controlled atmosphere storage. This has been 
accomplished with no sacrifice in storage life as compared with ordinary cold storage at $32^{\circ} \mathrm{F}$. Another disorder that is reduced in controlled atmosphere storage is wilting or shrivelling. If moisture from the apple can be retained in the storage room further losses from the apple can be prevented. Since the room is sealed this avenue of moisture escape is blocked.

It has been found, too, that apples from controlled atmosphere storage stand up longer on removal from storage. During the latter part of January, MeIntosh apples from ordinary storage usually show signs of mealiness and lack of flarour in about five days at $65^{\circ} \mathrm{F}$. The same apples in controlled atmosphere, although appearing about the same on removal, require eight to nime days to reach the same stage as those held in ordinary storage.

One somewhat debatable drawback of controlled atmosphere storage is that it is generally believed that superficial scald is more apparent under this method. Effective control can however be achieved by using oil wraps or shredded oil paper. If apples are destined for controlled atmosphere storage this treatment should be given.

TABLE I-CONTROL OF CORE FLUSH IN MCINTOSH APPLES BY CONTROLLED ATMOSPHERE STORAGE

\begin{tabular}{|c|c|c|c|c|c|c|}
\hline $\begin{array}{l}\text { Source of } \\
\text { Material }\end{array}$ & $\begin{array}{l}\text { Apple } \\
\text { Size }\end{array}$ & Year & $\begin{array}{l}\text { Type of } \\
\text { Storage }\end{array}$ & Temp. & $\begin{array}{c}\text { Storage Elapse } \\
\text { before } \\
\text { Examination }\end{array}$ & $\begin{array}{l}\text { Core Flush } \\
\text { Per Cent }\end{array}$ \\
\hline \multirow[t]{6}{*}{ Standard Orchard... } & $22_{2}^{\prime \prime}$ and up & 1937 & ordinary & $32^{\circ} \mathrm{F}$ & 147 days & $73 \cdot 2$ \\
\hline & $2 \frac{1}{4}^{\prime \prime}-2 \frac{1}{2}^{\prime \prime}$ & & & & & $35 \cdot 0$ \\
\hline & $2^{\prime \prime}-2 \frac{1}{4}^{\prime \prime}$ & & & & & $16 \cdot 0$ \\
\hline & $2 \frac{1}{2} "$ and up & & controlled & $39^{\circ} \mathrm{F}$ & 147 days & 0 \\
\hline & $2 \frac{1}{4}^{\prime \prime}-2 \frac{1}{2}^{\prime \prime}$ & & & & & 0 \\
\hline & $2^{\prime \prime}-2_{4}^{1 \prime \prime}$ & & & & & 0 \\
\hline \multirow[t]{4}{*}{ Susceptible to core flush-A. } & $2 \frac{1}{2}{ }^{\prime \prime}-23^{3 \prime \prime}$ & 1938 & ordinary & $32^{\circ} \mathrm{F}$ & 116 days & $38 \cdot 0$ \\
\hline & $2 \frac{1}{2}{ }^{\prime \prime}-2 \frac{3}{4}{ }^{\prime \prime}$ & & $\begin{array}{l}\text { controlled } \\
\text { atmosphere }\end{array}$ & $39^{\circ} \mathrm{F}$ & 116 days & $4 \cdot 0$ \\
\hline & $2 \frac{1}{2}^{\prime \prime}-2 \frac{3}{4}^{\prime \prime}$ & 1938 & ordinary & $32^{\circ} \mathrm{F}$ & 116 days & $16 \cdot 6$ \\
\hline & $2 \frac{1}{2}{ }^{\prime \prime}-2 \frac{3}{4}^{\prime \prime}$ & & $\begin{array}{l}\text { controlled } \\
\text { atmosphere }\end{array}$ & $39^{\circ} \mathrm{F}$ & 116 days & 0 \\
\hline
\end{tabular}

Another point is that once the room is sealed it must remain so for a long period. This means that the apples and the storage room cannot be cxamined during this time. If, however, good fruit is stored and outside temperature indicators are used, no harm or inconvenience should result.

\section{Selection of Gas Mixture}

The concentration of carbon dioxide and oxygen is the important factor in controlled atmosphere storage. Increasing the carbon dioxide and decreasing the oxygen supply slows down the life processes. The important factor is to have the carbon dioxide and oxygen balanced in such a way as to do no harm to the apples. Mixtures employed in controlled atmosphere storage are of two types; (1) normal oxygen, and (2) sub-normal oxygen. Extra equipment, a scrubber, and more efficient gas-tighting materials are required for the latter. 
In normal oxygen gas mixtures the carbon dioxide and oxygen total 21 per cent -5 per cent carbon dioxide with 16 per cent oxygen, 7 per cent carbon dioxide with 14 per cent oxygen, etc. Sub-normal oxygen mixtures have totals of less than 21 per cent-5 per cent carbon dioxide with 5 per cent oxygen, 5 per cent carbon dioxide with $2 \cdot 5$ per cent oxygen, etc. Before constructing a controlled atmosphere storage, the type of gas mixture to be used should be decided.

\section{Construction of the Gas Chamber}

The size of the gas chamber is not an important factor from the standpoint of operation but a large room will of course necessitate greater ventilation capacity and more scrubbing. Ideally the room should be just large enough to be completely filled. This means that the ratio of volume of air to apples is reduced making it easier to attain the desired atmospheric condi-。 tions. The ratio of room surface to fruit volume is also reduced. This is effective in making up gas losses that may occur through inefficient gas tighting. In addition controlled atmosphere storage is primarily used for the long storage holdings, and the room or rooms should be of a convenient size to hold the fruit destined for the later market.

\section{Making the Chamber Gas Tight}

Of the systems in use at present, the most efficient but the most costly is metal lining. A 28-gauge sheet metal is effective and is essential for subnormal atmospheres. Since these gas mixtures are induced by gas absorption, suction pressures in the room result. Another system makes use of gas tighting paints or sealing compounds. These are less costly and are effective for normal oxygen gas mixtures.

(1) Metal Lining.- The metal sheets should be nailed to the studding or furring strips with a $1 \frac{1}{2} "-2^{\prime \prime}$ overlap and the joints well sealed with caulking compound. Broad-headed nails should be used and these, of course, should be puttied or sealed with a gas tighting compound. Only sufficient nails to make secure construction should be used; spacings of $1 \frac{1}{2}^{\prime \prime}-2 \frac{1}{2}^{\prime \prime}$ should be ample. Instead of having the overlap nailed the joints can be soldered. If this is done a double lap roof type joint should be made to protect the seam from breaking due to expansion or contraction of the metal. The floor should have a wooden sub-floor under the sheet metal sufficiently strong to carry the weight of the fruit without bending or moving. Any movement is likely to cause binding or twisting of the metal, which would result in gas leakage. It is a good precaution to thoroughly paint all metal surfaces with corrosion-resistant paint. Various commercial products are available for applying to the walls, ceiling and floor of the storage room in order to make them impervious to the diffusion of carbon dioxide and oxygen. Applications of aluminum paint or ordinary floor paint on top of these will help to preserve the impervious surface. Precautions need to be taken also to scal all openings through which piping or wiring enter the room.

In a new storage plant it is usually part of the insulation contract to provide a gas tight seal on floor, walls, and ceiling. This is done by using different asphalt compounds, metal foils or combinations of these.

\section{Gas Tighting Paints}

The following is a description of the method employed in the construction of a controlled atmosphere room and its operation at the Horticultural Division, Central Experimental Farm, Ottawa. 
Such commercial preparatory products as "Sealapore," "Nerolac" and "Arcomastic" were used but are not specifically recommended. They proved to be quite satisfactory but there may be otlicr commercial products which would have been equally satisfactory.

The storage room has a rough plaster ceiling and walls and a concrete floor. The first step was to makie all these surfaces impervious to the diffusion of carbon dioxide and oxygen. To do this the door and door-frame were removed, all electrical connections and plugs were either removed or submerged below the wall or ceiling surface so that they could be plastered over. The brine coils were disconnected and taken down. The ceiling, walls and floor were all given two thorough coats of Scalapore, one coat of Nerolac, and the ceiling and walls were given an additional coat of aluminum paint. Floor paint (instead of aluminum paint) was applied to the floor to preserve the Nerolac surface. All holes and spaces which were in the ceiling where the brine coils were held in position were filled with vaseline. The bolts were inserted and the space left was filled up with Arcomastic. In addition, rubber washers were used at all joints to render them gas-tight. The brine coils were then put up and reconnected.

\section{Sealing the Door}

All possible openings in the door frame should be sealed with vaseline, and large spaces covered with paper plastered with vaseline. The best way to seal the door opening itself is with a sheet of aluminum about $3 / 16$ inches thick, the same size as the opening bolted to a rectangular steel frame.

The rectangular frame can be made of $\frac{1}{4}$-inch boiler plate with outer dimensions the same as those of the wooden door frame. The frame should extend 2 to 3 inches inside the wooden door frame to provide a flat surface to attach the aluminum sheet. A gasket of flexible rubber, 3 to 4 inches wide should be placed between the faces of the wooden door frame and the metal frame. The metal frame can then be attached to the wooden door frame with lag screws (about 12-inch centres is sufficient). A 2- to 3-inch sill should be placed at the base of the door frame to complete the seal all around.

Holes should be drilled and threaded around the inner exposed surface of the metal frame at about 5 -inch centres. These must match exactly similar holes (unthreaded) in the aluminum sheet. The aluminum sheet may then be attached to the metal frame with studs. A flexible rubber gasket between the two metal surfaces and tightening the nuts completes the seal.

A good inspection window may be made with plate glass sealed over a cut-out opening in the aluminum sheet. A thermometer suspended in the storage room near the window can be read easily. Handles bolted or welded to the aluminum sheet will facilitate handling. These should not project far enough to interfere with the standard outer storage door.

\section{Electrical Gas Tube Connections, etc.}

For the admission of clectrical wiring, etc., 2-inch black iron conduit is suitable. This should be inserted through the outer wall of the storage so that the inner and outer openings are flush with the wall surface. Rubber stoppers can be obtained for either end of the pipe. The wires may then be passed through the pipe and through holes bored in the rubber stoppers. When rubber stoppers are inserted in the pipe and smeared with vaseline they form a gas-tight seal. Any chinks around the conduit wire may then be filled with asphalt compound. This conduit should contain: 1 electric cable for 
temperature records, 1 electric cable for illumination, 1 tube for drawing off gas for gas analysis, 1 capillary tube for thermostat bulb, and also an electric cable for a circulation fan.

\section{Ventilation Equipment}

For ventilation purposes two galvanized iron pipes will be required-one conduit for an inlet, the other for an outlet. The inlet pipe can extend to the back of the storage room, and the end outside the storage should have a snugfitting metal cap. The outlet tube should extend just through the wall of the storage. Near the wall outside the storage the tube should have a sliding damper and then flare out to encase a small electric fan. When the room requires ventilation the cap on the inlet tube is removed, the outlet damper opened and the fan started. In this way air is drawn from the room and replaced with outside air.

For sub-normal oxygen mixtures, in addition to the equipment already described, a scrubber for removing carbon dioxide without admitting oxygen has to be installed.

\section{Gas Analysis}

Checking the concentration of carbon dioxide (and oxygen in the case of sub-normal oxygen atmospheres) is essential every twenty-four hours. This procedure requires only a few moments and can be carried out easily with the Lunge Nitrometer equipment. A description of this operation is given in Fig. 18 and in the following paragraphs.

By squeezing Bulb B several times the line A from the storage chamber is filled with gas from this chamber. When all contaminating air has been pumped out by this means a sample can be drawn into burette $\mathrm{C}$. In order to do this the burette must be filled with water from levelling bulb $\mathrm{D}$. This is done by turning stopcock $\mathrm{E}$ so that port $\mathrm{F}$ is open and raising levelling bulb $\mathrm{D}$ until the burette $\mathrm{C}$ is completely filled with water, and a slight amount goes into cup $\mathrm{H}$. Then $\mathrm{E}$ is turned until port $\mathrm{G}$ is open to burette. By lowering the levelling bulb a sample of air is drawn in. By holding the levelling bulb close to the burette a 50 cc. sample of gas is measured, making sure that the water level is at the 50 mark, and this in turn is level with the water in the levelling bulb. Stopcock $\mathrm{E}$ is then turned so that both ports are closed.

After the sample of gas is in the burette the next step is to absorb the carbon dioxide. This is done by first pouring a 30 per cent potassium hydroxide solution into cup H. (This cup should never be allowed to be completely emptied during analysis.) By turning stopeock $\mathrm{E}$ some of the solution is allowed to pass into the burette. It will be noted that the water level in the burette has risen, when the water in the bulb is held at the same level as in the burette. Additional portions of the potassium hydroxide solution are allowed to flow into the burette until the water level ceases to rise (i.e. when readings indicate that no carbon dioxide remains in the gas sample). If the original volume of the gas sample was $50 \mathrm{cc}$. and if the volume after carbon dioxide removal is $40 \mathrm{cc}$. it is evident that the carbon dioxide concentration is 20 per cent $\left(50-40=10 \mathrm{cc}\right.$. of $\mathrm{CO}_{2}=1 / 5$ original $)$.

After the carbon dioxide has been removed the same procedure is used for oxygen, only instead of using potassium hydroxide, 10 per cent alkaline pyrogallol solution is used (20 grams pyrogallol in $200 \mathrm{ml}$. of 30 per cent 
potassium hydroxide). This latter solution absorbs both oxygen and carbon dioxide hence it is very important that the carbon dioxide be absorbed first by the potassium hydroxide in order to get true readings. Another important point is that all readings are made on a volumetric basis hence any change of temperature during analysis will affect the results. A water bath or jacket helps to correct this but will not give indefinite control.

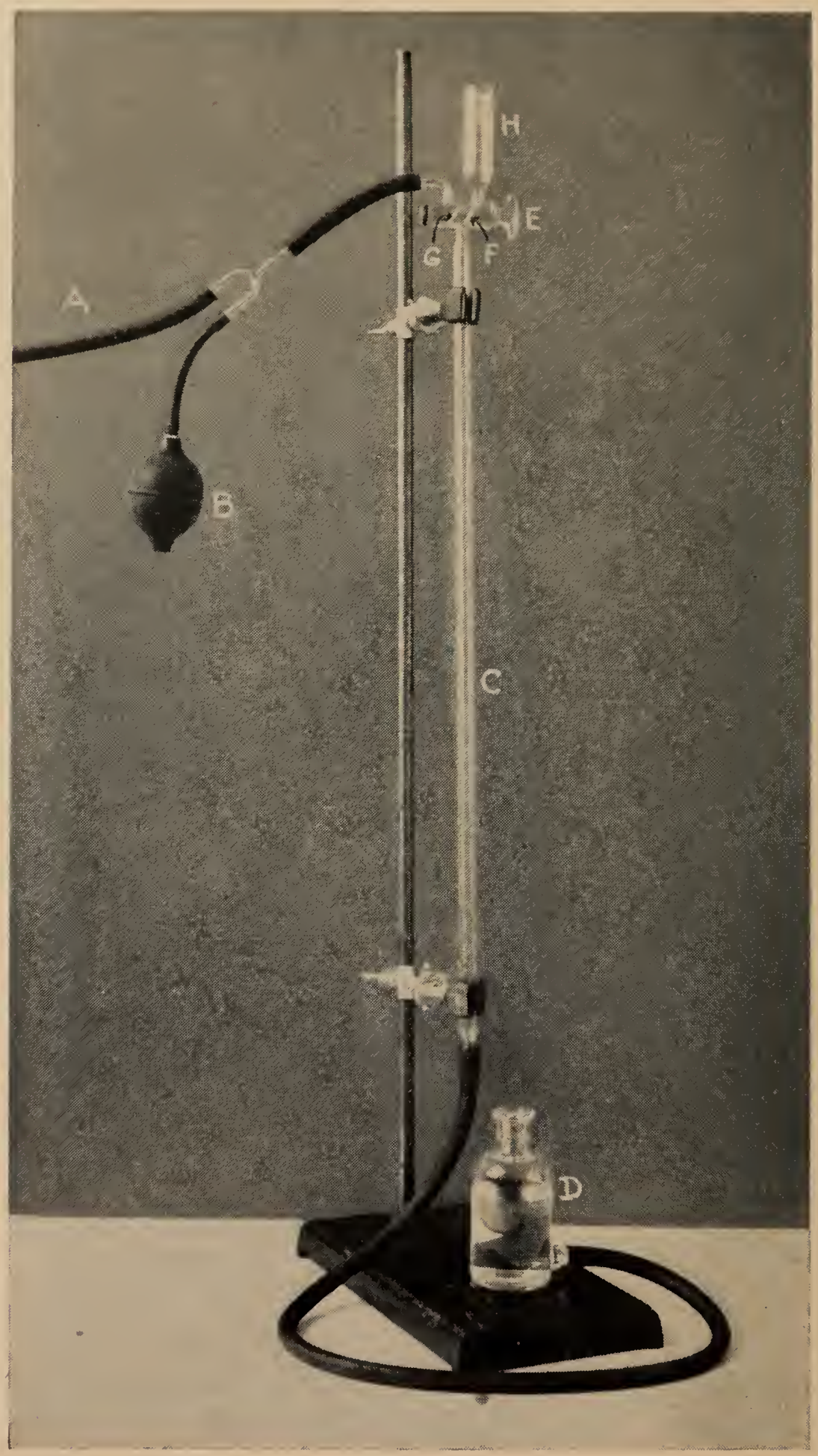

F'ig. 18. Lunge nitrometer for determining concentration of $\mathrm{CO}_{2}$ and $\mathrm{O}_{2}$. (See text for operation procedure.) 


\section{Operation}

\section{Normal Oxygen Mixture}

After the room has been constructed and found sufficiently gas tight it may be loaded and sealed. Routine daily gas analyses are then carried out. When carbon dioxide has reached or slightly exceeded the desired point some of the air in the room is exchanged for outside air until the concentration of carbon dioxide has been reduced to a safe point. The determining factor, in this regard, is the daily increment of carbon dioxide. This is usually determined by the daily analyses previous to the time when ventilation is required. Assuming that a 7 per cent carbon dioxide mixture is required, daily readings will start at 0 and gradually increase to 7 per cent. If towards the latter part of these series of analyses the daily increment is 1 per cent, then it would be safe to ventilate to $6 \frac{1}{4}$ to $6 \frac{1}{2}$ per cent so that the 7 per cent mark would be straddled during the following twenty-four hour period.

One feature which would save time and contribute towards efficient ventilation is to calculate the reduction of carbon dioxide in a given ventilation period. For example, it may be determined that for a 0.2 per cent reduction in carbon dioxide a five-minute ventilation period is needed. If 1 per cent reduction is required, then a twenty-five minute ventilation period is needed; for 0.8 per cent reduction twenty minutes would be needed, etc.*. A diagrammatic layout of a ventilation system is shown in Fig. 19.

\section{Sub-normal Oxygen Mixture}

The same method of operation is carried out with sub-normal oxygen mixtures as with normal oxygen mixtures except that carbon dioxide is removed by absorption instead of by ventilation as long as the oxygen concentration is adequate. Apparatus for this purpose is shown in Fig. 20. The principle of this equipment is that air is drawn from the room by a fan. This air passes through a caustic soda spray which absorbs the carbon dioxide. This air is then returned to the sealed storage room. When the daily analysis shows that the oxygen concentration is below the required level, fresh air is admitted as described for normal oxygen ventilation.

\section{Varietal Recommendations}

Controlled atmosphere storage is somewhat further complicated by the fact that different varieties may require different carbon dioxide, oxygen, and temperature conditions. Stage of maturity also influences the results obtained in this type of storage in much the same way as in ordinary cold storage. The following results, however, are based on ideal harvesting, packing, and general handling methods as outlined elsewhere in this bulletin.

Some workers claim that is it not good practice to store different varieties in the same chamber in spite of the fact that the same atmospheric and temperature conditions are recommended for these varieties. Earlier ripening varieties give off ethylene when ripe and may cause later varieties to mature earlier than they otherwise would. In addition a moderately scald-resistant variety like McIntosh might, under certain circumstances, produce aldehydes, resulting in the production of superficial scald in more susceptible varietics. According to preliminary results, however, no deleterious effects were found at Ottawa by storing McIntosh, Fameuse and Golden Russet in the same chi.nber.

* This is not true for all conditions, because as the concentration of $\mathrm{CO}_{2}$ is reduced longer ventilation is required for a given percentage reduction. 'This is, however, satisfactory from a practical standpoint. 
As a matter of fact the flavour of the Golden Russet seemed to be improved. None of these varicties is classed as highly susceptible to superficial scald, but there is a considerable variation in their rates of ripening.

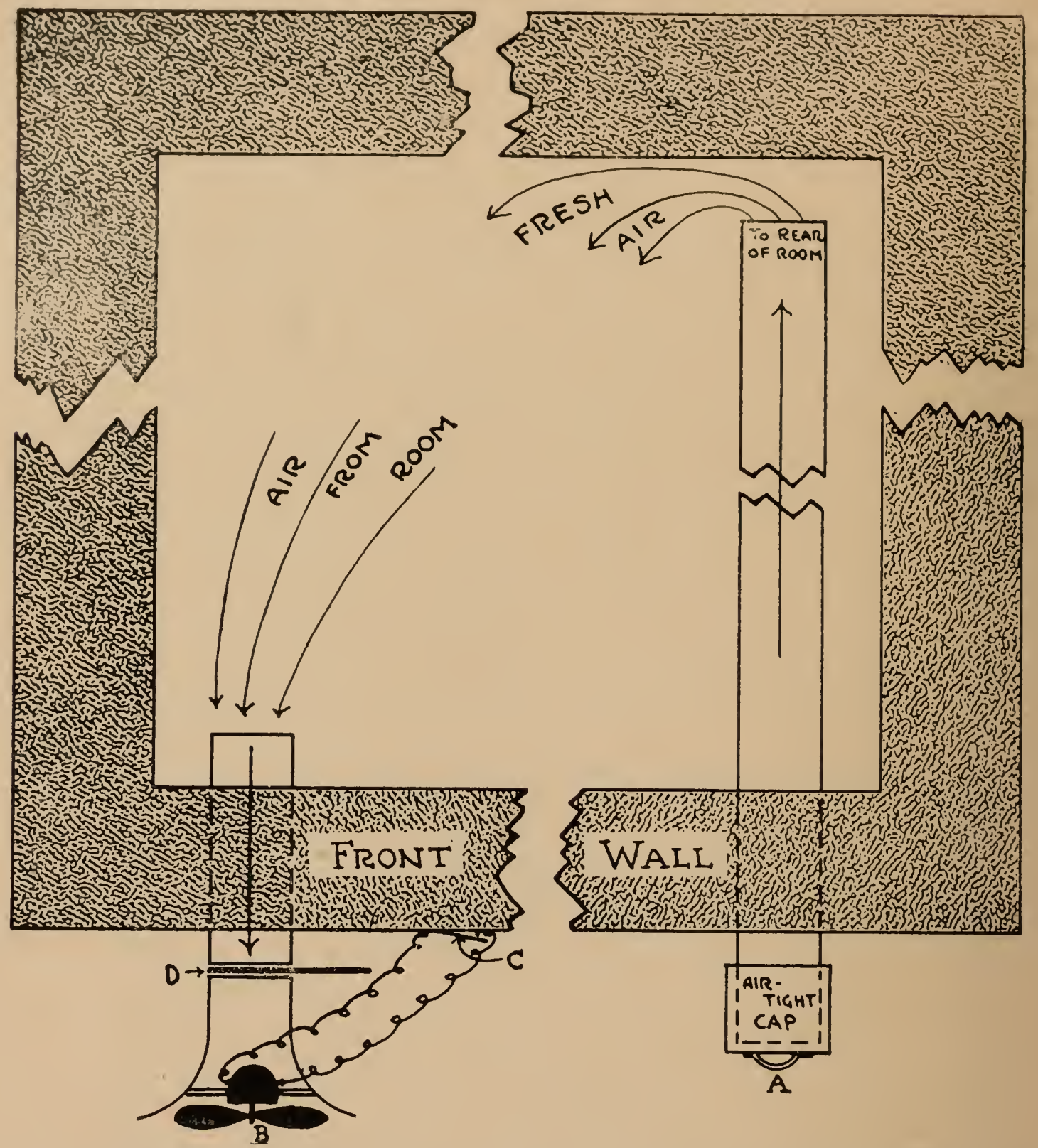

Fig. 19. Diagrammatic layout for ventilation system in controlled atmosphere storage room.A Inlet cap to be removed for ventilation; B Fan for pulling air from room; C Control switch for fan; D Damper for regulating outward flow of air from room.

It should be noted that experiments have progressed much further with varieties like McIntosh, Golden Russet, and Cox Orange than with other varieties. For this reason information on atmospheric and temperature conditions may be modified by future work on these "other varieties".

McIntosh.-Storage life is prolonged and core flush adequately controlled in either a 7 per cent carbon dioxide and 14 per cent oxygen or a 5 per cent carbon dioxide and 2.5 per cent oxygen mixture at $39^{\circ} \mathrm{F}$. The latter is better than the former, but since it is a sub-normal oxygen mixture it is more expensive from the standpoint of storage construction.

Recently, investigations have been conducted with temperatures lower than $39^{\circ} \mathrm{F}$. with 5 per cent carbon dioxide and 16 per cent oxygen. Because of increased external carbon dioxide injury it would appear that $34^{\circ} \mathrm{F}$. is the limit of temperature reduction. 
Golden Russet.-A 5 per cent carbon dioxide and $1 \hat{b}$ per cent oxygen mixture at $32^{\circ} \mathrm{F}$. has worked out satisfactorily for this variety. In a commercial trial retention of moisture and flavour were noted. These apples met with favour when marketed.

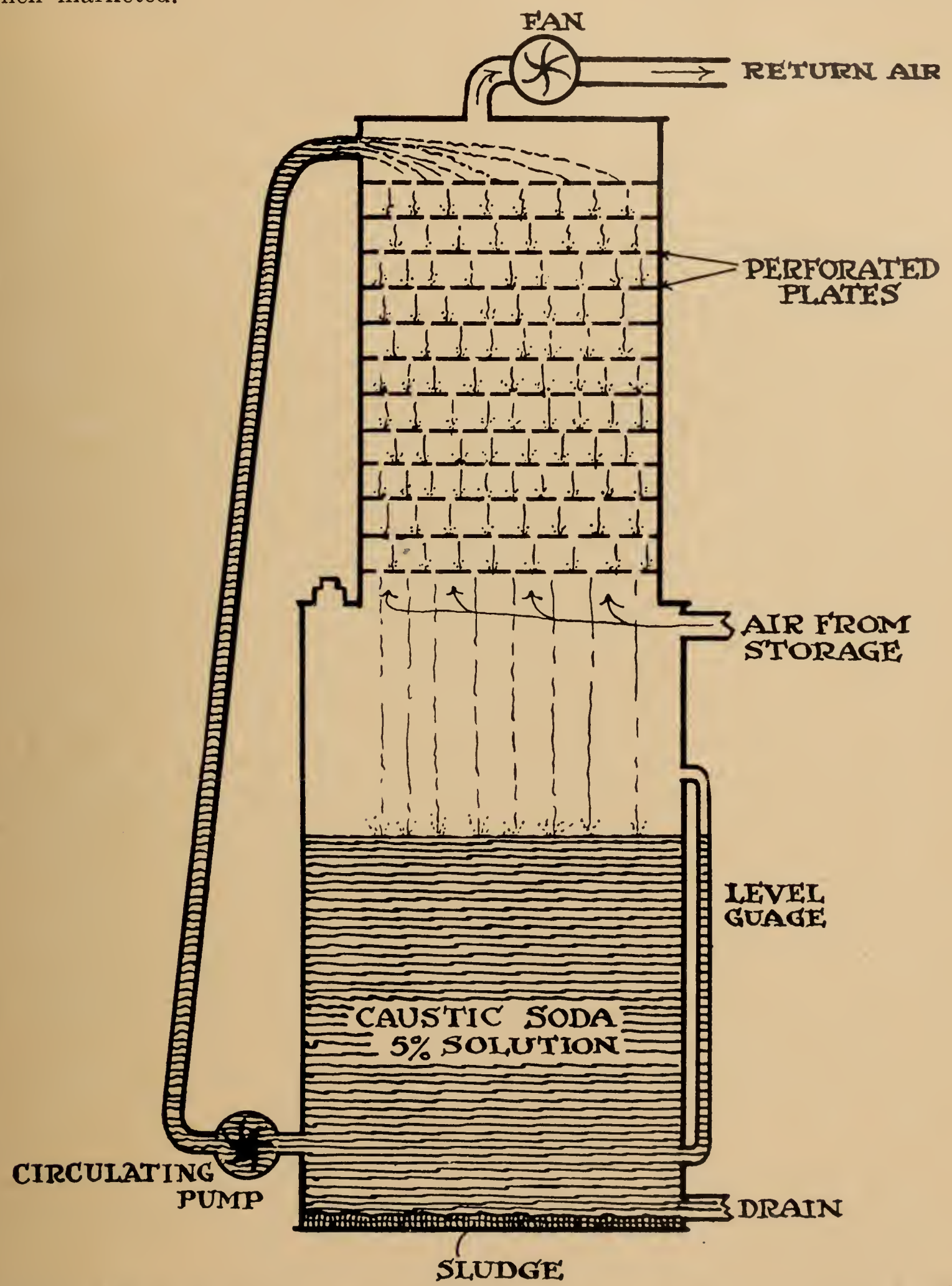

FIG. 20. Longitudinal section of atmospheric washer used for removal of carbon dioxide. (From Smock and Van Doren, Cornell Bull. 762)

Cox Orange Pippin.-This variety unfortunately suffers from low-temperature breakdown at $36^{\circ} \mathrm{F}$. and lower. If held at safe temperatures $\left(39^{\circ} \mathrm{F}\right.$.) the normal storage life cannot be extended beyond the middle of December. Controlled atmosphere storage in preliminary trials has made it possible to 
carry Cox Orange well beyond the Christmas market. A 5 per cent carbon dioxide and 5 per cent oxygen mixture at $39^{\circ} \mathrm{F}$. has been found best for this variety. Howerer, good results were obtained with a 5 per cent carbon dioxide and 16 per cent oxygen mixture at $39^{\circ} \mathrm{F}$. If the latter mixture is used it should not be continued after December 1 or when the apples are approaching prime ripeness. At this time normal atmospheric storage at $39^{\circ} \mathrm{F}$. should be used and should be adequate to carry the apples to the end of January. It would appear that this rariety becomes susceptible to carbon dioxide injury (brownleart) when the full-ripe stage is approached.

Lobo.-Preliminary results indicate that 9 per cent carbon dioxide and 12 per cent oxygen at $39^{\circ} \mathrm{F}$. is best for this variety. In general, however, Lobo cannot be considered a controlled atmosphere apple, because small differences in maturity cause serious results. The correct stage is when the apples are one-half to three-quarters blushed, starch test of No. 1 (ground colour and pressure tests are unreliable for this variety). If the maturity is slightly beyond this, breakdown may result.

Gravenstein.-Preliminary tests show that a 10 per cent carbon dioxide and $2 \cdot 5$ per cent oxygen mixture at $39^{\circ} \mathrm{F}$. is satisfactory for this varicty.

Fameuse.-A mixture of 5 per cent carbon dioxide and 16 per cent oxygen at $32^{\circ} \mathrm{F}$. appears best for this variety. This increases storage life about 75 per cent but has a tendency to develop a slightly woody texture in the apples.

Northern Spy.-Maturity is important with this variety. If over-mature, carbon dioxide injury is likely to develop in any of the mixtures tried. However, excellent results were obtained in preliminary trials with 7 per cent carbon dioxide and 14 per cent oxygen mixture at $32^{\circ} \mathrm{F}$. when the apples were harvested in a fairly immature stage; one-third to three-quarters coloured, 1-3 starch test and $17 \frac{1}{2}$ pounds pressure test (ground colour appears unreliable for this variety).

Sandow.-Preliminary tests show that 9 per cent carbon dioxide and 12 per cent oxygen at $32^{\circ} \mathrm{F}$. is satisfactory for this variety. Under these conditions Sandow was held in good storage condition until June.

Delicious.-Carbon dioxide hastens the onset of mealiness, a characteristic termination of storage life of this variety. Reduced oxygen however, prolongs storage life and either a $2 \cdot 5$ per cent or 5 per cent oxygen mixture in the absence of carbon dioxide may be used. Since the former is accompanied by a slight increase in scald susceptibility the 5 per cent oxygen mixture is more satisfactory.

Cortland.-Maturity is important in this variety. If harvested with ground colour of 5 or more, starch test 5-7 and a pressure of 15 pounds, Cortland does well in a 7 per cent carbon dioxide and 14 per cent oxygen mixture at $39^{\circ} \mathrm{F}$. If harvested in a less mature. stage Cortland fails to develop quality in controlled atmosphere storage.

Lawfam, King, Jonathan, Rhode Island Greening and Baldwin.-Experiments with these varieties so far show no advantage over ordinary storage.

\section{Storage Notes on Varieties}

As a general rule $32^{\circ} \mathrm{F}$. and 90 per cent relative humidity provide the best storage conditions for apples. As would be expected, some varieties keep longer than others. Frequently apples suffer from breakdown at $32^{\circ} \mathrm{F}$. which can be avoided by storing at higher temperatures. Various other conditions may terminate the storage life of different varieties. In some varieties physiological or fungal disorders are responsible while with others it may be lack of quality or some other cause. The following represents a summary of findings on storage characteristics for some of the more important apple varieties. Since all varieties are subject to fungal rots, particularly when mature, this disorder is not mentioned in the summary. 
Baldwin.-There is usually little difficulty with this variety at $32^{\circ} \mathrm{F}$. and 90 per cent relative humidity. The storage life is usually to March at which time senility sets in. Bitter pit or storage pit frequently occurs on Baldwin. Care in selecting apples from orchards free from bitter pit controls this trouble. If bitter pit is present in the orchard the apples should be left on the tree as long as possible so that pitted apples may be culled before storage.

Bancroft.-This variety does well at $32^{\circ} \mathrm{F}$. and 90 per cent relative humidity. The storage life is terminated chiefly by the onset of rots and loss of quality. Estimate of storage life is presently rated as being the end of March.

Ben Davis.-This variety should be stored at $32^{\circ} \mathrm{F}$. and 90 per cent relative humidity. It will possibly stand more abuse than any other variety, and can be stored until May.

Cortland.-The best storage conditions for Cortland are $32^{\circ} \mathrm{F}$. and 90 per cent relative humidity. Storage life is terminated about the middle of February by the onset of core flush and by the development of a dry woody texture. This variety is susceptible to an undetermined disorder that takes the form of hardening or drying out of the tissues in the core area. In samples observed this does not appear to be serious. As with McIntosh maturity of harvest seems to be important with Cortland. If allowed to reach maturity on the tree the storage quality is very much improved.

Cox Orange.-This variety is extremely susceptible to breakdown at $32^{\circ} \mathrm{F}$. Hence it should be stored above $36^{\circ} \mathrm{F}$. with 90 per cent relative humidity. Controlled atmosphere storage will extend the storage life to the end of January otherwise December is the limit of storage life because of the onset of senility.

Delicious.-This is a mild flavoured apple which depends on its high moisture content and crisp texture for appeal. At $32^{\circ} \mathrm{F}$. and 90 per cent relative humidity it can be held until March before becoming mealy. Care should be taken with this varicty to see that it can stand up a week at least after removal from storage before mealiness sets in.

Fameuse.-If stored at $32^{\circ} \mathrm{F}$. and 90 per cent relative humidity this variety can be held until December. At this time or later loss of quality is evident followed by the onset of mealy breakdown. Core flush usually develops during November if stored at $39^{\circ} \mathrm{F}$. or higher.

Golden Russet.-High humidity is required for this variety because of its high susceptibility to shrivelling, hence 95 per cent relative humidity at $32^{\circ} \mathrm{F}$. provides the best storage conditions. If shrivelling is controlled this variety can be marketed to late April. General loss of quality is the limiting factor of storage life. A form of lenticel spotting may cause trouble in storage, but this condition is not common.

Gravenstein.-This variety is susceptible to low-temperature breakdown at temperatures below $36^{\circ} \mathrm{F}$. particularly if harvested at late maturity. Hence $36^{\circ} \mathrm{F}$. and 90 per cent relative humidity are considered best. This is a short life apple being bcyond marketability at the end of November.

Jonathan.-When stored at $32^{\circ} \mathrm{F}$. and 90 per cent relative humidity Jonathan can be held until the end of January. Jonathan breakdown may develop in several weeks if harvested when too mature. Lower temperatures delay the onset of this disorder. When harvested and stored properly general softening, loss of quality, and possibly Jonathan spot may determine the end of storage life.

King.-The most satisfactory storage conditions for this variety are $36^{\circ} \mathrm{F}$. and 90 per cent relative humidity. Core flush and brealidown are inclined to develop at $32^{\circ} \mathrm{F}$. At about the end of January, even under the best conditions, King becomes over-ripe. 
Laufam.-This variety appears to be free of physiological disorders; fungal rots and loss of quality terminate storage life. Lawfam can be held at $32^{\circ} \mathrm{F}$. and 90 per cent relative humidity to the end of March; and appears to show a good response to activated charcoal air filtration. Care should be taken not to store Lawfam with carly maturing varicties of apples.

Lobo.- Senile breakdown is the chief limiting factor in storing this variety. Maturity at harrest does not appear to materially affect the amount of physiological disorders but later harvest improves eating quality. Growing areas in which this variety develops slowly are conducive to long storage life. In general, it is not considered safe to hold Lobo beyond the end of December. The recommended storage conditions are $32^{\circ} \mathrm{F}$. and 90 per cent relative humidity. Low temperature breakdown has been found at this temperature but usually does not derelop until January.

McIntosh.-At $32^{\circ} \mathrm{F}$. and 90 per cent relative humidity this variety can be stored satisfactorily until the end of January. At this time McIntosh may still look acceptable but the quality will have deteriorated to a low level. High nitrogen or unbalanced feeding, light crop, or immature harvest will cause core flush development when stored at $32^{\circ} \mathrm{F}$. Apples harvested under these conditions should be stored at $39^{\circ} \mathrm{F}$. until the ground colour shows a slight tendency to yellow, then the temperature should be reduced to $32^{\circ} \mathrm{F}$.

Newtown.-This variety keeps satisfactorily until May at $32^{\circ} \mathrm{F}$. and 90 per cent relative humidity. Harvesting at the proper maturity is important since early or immature harvest results in core flush, superficial scald and, where susceptible, bitter pit. Oil paper wrapping or shredded oil paper are effective in controlling superficial scald. Apples from light-crop trees and those harvested too early should be stored at higher temperatures and marketed early.

Northern Spy.-Because of late maturity, and highly aromatic flavours this variety is one of the longest kecpers. At $32^{\circ} \mathrm{F}$. and 90 per cent relative humidity Northern Spy can be held in good condition until April. On rare occasions it has been known to develop low-temperature breakdown (soft scald type). Sometimes too, storage pit may be present. The latter disorder may be avoided by delayed harvest since the pit-susceptible apples can be discarded before storage. Many storage operators prefer to delay grading this variety until December because of susceptibility to bruising when hard and crisp. Storage life normally is terminated by senility and the onset of rots.

Rhode Island Greening.-When stored at $32^{\circ} \mathrm{F}$. and 90 per cent relative humidity this variety will store to the end of February. Superficial scald is the main storage disorder. Late harvest and oil paper are the most common means of controlling this trouble. Greenings have been known to develop core flush but this appears to be a seasonal factor, which is evidently not controlled by temperature or maturity at harvest.

Rome Beauty.-This variety if stored at $32^{\circ} \mathrm{F}$. and 90 per cent relative humidity can be held to late March or early April. Storage life is usually terminated by loss of quality, softening, and general deterioration.

Spartan.-Accurate information on the storage behaviour of this variety has not yet been obtained, but it would appear that Spartan exceeds McIntosh in storage life. Spartan has been known to be subject to breakdown in storage but it is thought that weather conditions during harvest are more responsible than storage conditions. 
EXPERIMENTAL FARMS SERVICE

Director, E. S. Hopkins, B.S.A., M.Sc., Ph.D.

Central Experimental Farm, Ottawa, Ontario

Division

Animal Husbandry

................................

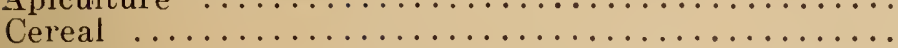

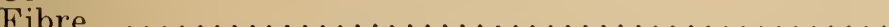

Field Husbandry, Soils \& Agricultural Engineering ..

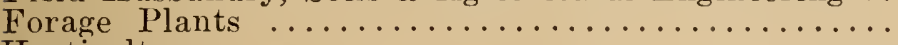

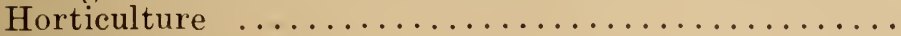

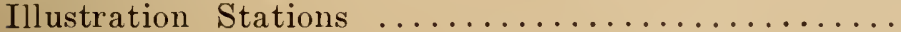

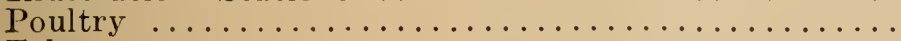

Tobacco

NEWFOUNDLAND

Officer-in-Charge, Experimental Station, St. John's, I. J. Green, B.S.A.

\section{PRINCE EDWARD ISLAND}

Superintendent, Experimental Station, Charlottetown, R. C. Parent, B.S.A., M.Sc.

Superintendent, Experimental Fur Ranch, Summerside, C. K. Gunn, B.Sc., M.Sc., Ph.D.

\section{NOVA SCOTIA}

Superintendent, Experimental Farm, Nappan, S. B. Williams, B.S.A., M.Sc.

Superintendent, Experimental Station, Kentville, C. J. Bishop, B.Sc., A.M., Ph.D.

\section{NEW BRUNSWICK}

Superintendent, Experimental Station, Fredericton, S. A. Hilton, B.S.A., M.S.A.

\section{QUEBEO}

Superintendent, Experimental Station, Lennoxville, E. Mercier, B.Sc., M.Sc., Ph.D.

Superintendent, Experimental Station, Ste. Anne de la Pocatiere, J. R. Pelletier, B.S.A., M.A., M.Sc.

Superintendent, Experimental Station, L’Assomption, R. Bordeleau, B.S.A.

Superintendent, Experimental Station, Normandin, A. Belzile, B.S.A.

Officer-in-Charge, Experimental Substation, Caplan, L. J. Bellefleur, B.S.A.

Officer-in-Charge, Experimental Substation, Ste. Clothilde, F. S. Browne, B.S.A.

Central Experimental Farm, Ottawa.

\section{ONTARIO}

Superintendent, Experimental Station, Kapuskasing, F. X. Gosselin, B.S.A.

Sunerintendent, Experimental Station, Harrow. H. F. Murwin, B.S.A.

Officer-in-Charge, Experimental Substation, Delhi, L. S. Vickery, B.S.A., M.Sc.

Officer-in-Charge, Experimental Substation, Smithfield, D. S. Blair, B.S.A.. M.Sc.

Officer-in-Charge, Experimental Substation, Woodslee, J. IV. Aylesworth, B.S.A., M.S.

\section{MANITOBA}

Superintendent, Experimental Farm, Brandon, R. M. Hopper, B.S.A., M.Sc.

Superintendent, Experimental Station, Morden, W. R. Leslie, B.S.A.

Officer-in-Charge, Pilot Flax Mill, Portage la Prairie, E. M. MacKey, B.S.A.

\section{SASKATCHEWAN}

Superintendent, Experimental Farm, Indian Head, J. G. Davidson, B.A., B.S.A., M.S.A.

Superintendent, Experimental Station, Swift Current, G. N. Denike, B.S.A.

Superintendent, Experimental Station, Scott, G. D. Matthews, B.S.A.

Superintendent, Experimental Station, Melfort, H. E. Wilson, B.S.A.

Superintendent, Experimental Substation, Regina. J. R. Foster, B.S.A

Superintendent, Forest Nursery Station, Indian Head, John Walker, B.Sc., M.S.

Superintendent, Forest Nursery Station, Sutherland, W. L. Kerr, B.S.A., M.Sc.

\section{ALBERTA}

Superintendent, Experimental Station, Lacombe, G. E. DeLong, B.S.A., M.Sc.

Superintendent, Experimental Station, Lethbridge, A. E. Palmer, B.Sc.. M.Sc.

Superintendent, Experimental Station, Beaverlodge, E. C. Staccy, B.A., M.Sc.

Superintendent, Range Experiment Sation, Manyberries, H. F. Peters. B.S.A.

Officer-in-Charge, Experimental Substation, Fort Vermilion, V. J. Lowe.

\section{BRITISH COLUMBIA}

Superintendent, Expcrimental Farm, Agassiz, W. H. Hicks. B.S.A.

Supcrintendent, Experimental Station, Summerland, R. C. Palmer, B.S.A.. M.Sc., D.Sc.

Superintendent, Experimental Station, Prince George, F. V. Hutton, B.S.A.

Superintendent, Experimental Station, Saanichton, J. J. Woods. B.S.A.. M.S.A.

Superintendent, Experimental Substation. Smithers, W. T. Burns. B.S.A., M.Sc.

Superintendent, Range Experiment Station, Kamloops, T. G. Willis, B.S.A.. M.S.A

\section{YUKON AND NORTHWEST TERRITORIES}

Officer-in-Charge, Experimental Substation, Whitehorse, Y.T.. J. W. Abbott.

Officer-in-Charge, Experimental Substation, Fort Simpson, N.W.T., J. A. Gilbey, B.S.A.. M.Sc. 
